Technological University Dublin

DÜBLIN

ARROW@TU Dublin

\title{
A Rational Design of a Selective Inhibitor for Kv1.1 Channels Prevalent in Demyelinated Nerves That Improves Their Impaired Axonal Conduction
}

\author{
Ahmed Al-Sabi \\ Dublin City University \\ Declan Daly \\ Dublin City University \\ Patrick Hoefer \\ Dublin City University
}

See next page for additional authors

Follow this and additional works at: https://arrow.tudublin.ie/schfsehart

Part of the Chemicals and Drugs Commons, Medical Sciences Commons, and the MedicinalPharmaceutical Chemistry Commons

\section{Recommended Citation}

J. Med. Chem. 2017, 60, 6, 2245-2256 Publication Date:February 22, 2017 DOI: 10.1021/ acs.jmedchem.6b01262

This Article is brought to you for free and open access by the School of Food Science and Environmental Health at ARROW@TU Dublin. It has been accepted for inclusion in Articles by an authorized administrator of ARROW@TU Dublin. For more information, please contact arrow.admin@tudublin.ie, aisling.coyne@tudublin.ie, gerard.connolly@tudublin.ie.

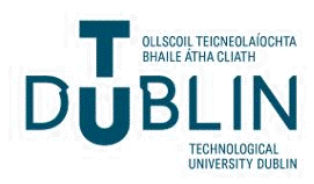




\section{Authors}

Ahmed Al-Sabi, Declan Daly, Patrick Hoefer, Gemma K. Kinsella, Charles Metais, Mark Pickering, Caroline Herron, Seshu Kumar Kaza, Kieran Nolan, and J. Oliver Dolly 


\title{
Journal of \\ Medicinal \\ Chemistry
}

\section{A Rational Design of a Selective Inhibitor for Kv1.1 Channels Prevalent in Demyelinated Nerves That Improves Their Impaired Axonal Conduction}

\author{
Ahmed Al-Sabi, ${ }^{\dagger, \#, \square}$ Declan Daly, ${ }^{\ddagger}, \#$ Patrick Hoefer, ${ }^{\ddagger}$ Gemma K. Kinsella, ${ }^{\S}$ Charles Metais, ${ }^{\dagger}$ \\ Mark Pickering, $"$ Caroline Herron, ${ }^{\perp}$ Seshu Kumar Kaza, ${ }^{\dagger}$ Kieran Nolan, ${ }^{*},{ }^{\ddagger}$ and J. Oliver Dolly ${ }^{* \dagger}$ \\ ${ }^{\dagger}$ International Centre for Neurotherapeutics and ${ }^{\ddagger}$ School of Chemical Sciences, Dublin City University, Glasnevin, Dublin 9, Ireland \\ ${ }^{\S}$ School of Food Science and Environmental Health, College of Sciences and Health, Dublin Institute of Technology, Cathal Brugha \\ Street, Dublin 1, Ireland \\ "UCD School of Medicine, University College Dublin, Dublin, Ireland \\ ${ }^{\perp}$ School of Biomolecular and Biomed Science, Conway Institute, Belfield, Dublin 4, Ireland
}

Supporting Information

\begin{abstract}
K}^{+}$channels containing $\mathrm{Kv} 1.1 \alpha$ subunits, which become prevalent at internodes in demyelinated axons, may underlie their dysfunctional conduction akin to muscle weakness in multiple sclerosis. Small inhibitors were sought with selectivity for the culpable hyper-polarizing $\mathrm{K}^{+}$currents. Modeling of interactions with the extracellular pore in a Kv1.1-deduced structure identified diaryldi(2-pyrrolyl)methane as a suitable scaffold with optimized alkyl ammonium side chains. The resultant synthesized candidate $\left[2,2^{\prime}-\left(\left(5,5^{\prime}\right.\right.\right.$ (di- $p$ topyldiaryldi(2-pyrrolyl)methane)bis (2,2' carbonyl)bis(azanediyl)) diethaneamine $2 \mathrm{HCl}$ (8) selectively blocked $\mathrm{Kv1} .1$ channels $\left(\mathrm{IC}_{50} \approx 15 \mu \mathrm{M}\right)$ recombinantly expressed in mammalian cells, induced a positive shift in the voltage dependency of $\mathrm{K}^{+}$current activation, and slowed its kinetics. It preferentially inhibited channels containing two or more Kv1.1 subunits regardless of their positioning in concatenated tetramers. In slices of corpus callosum from mice subjected to a demyelination protocol, this novel inhibitor improved neuronal conduction, highlighting its potential for alleviating symptoms in multiple sclerosis.
\end{abstract}

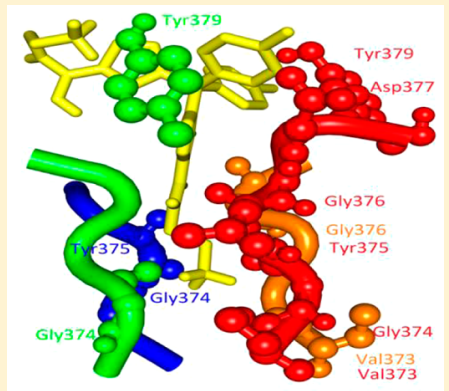

Interaction of 8 ( ) with Kv1 subunits

\section{INTRODUCTION}

$\mathrm{K}^{+}$channels are important for regulating membrane excitability, which in turn affects signal transmission. Voltage-gated $\mathrm{K}^{+}$ channels of the Shaker subfamily (Kv1) play vital roles in neurons by controlling cell excitability and synaptic transmission. These channels are involved in some human diseases ${ }^{1}$ with their vital functions altered by mutations (e.g., certain forms of epilepsy ${ }^{2}$ or truncation (e.g., Episodic ataxia type I). ${ }^{3}$ Kv1 channels purified from mammalian brain, using selective blockers, $\alpha$-dendrotoxin $(\alpha \mathrm{DTX})$ or $\mathrm{DTX}_{\mathrm{k}}$, are large (M.W. $\approx$ $400 \mathrm{k}$ ) sialoglycoprotein complexes, ${ }^{4}$ consisting of four poreforming $\alpha$ subunits and four cytoplasmically associated auxiliary $\beta$ proteins. ${ }^{5,6}$ When heterologously expressed, each of the major genes encoding $\alpha$ subunits $[\mathrm{Kv} 1.1-1.6]^{7-9}$ and $\mathrm{Kv} 1.7^{10}$ yields a homotetrameric channel with distinct biophysical and pharmacological profiles. Further diversity can be created in vivo by heteropolymerization, but only a subset of the possible oligomeric combinations have been isolated from mammalian brain, ${ }^{11-14}$ suggesting that their synthesis and/or assembly are restricted. Kv1.2 is the most prevalent in neuronal membranes where a portion occurs as a homotetramer and the majority is heteromerized with other $\mathrm{Kv1} \alpha$ subunits; ${ }^{11,14}$ interestingly, there is a preponderance of the less abundant Kv1.1 subunit in oligomers with Kv1.2.
Kv1 channels, exposed upon demyelination of axons in patients suffering from multiple sclerosis (MS), contribute to abnormal propagation of nerve signals and the resultant debilitating muscle weakness. ${ }^{15}$ Although aminopyridines can inhibit the latter channels, such therapy is only beneficial in the short term; also, their blockade of other $\mathrm{K}^{+}$channel types results in serious off-target effects, including seizures. ${ }^{15}$ Our observation of Kv1.1-containing channels being expressed ectopically in optic nerve demyelinated axons from mice fed cuprizone, ${ }^{16}$ mimicking changes in MS, has indicated the subtypes present. In fact, the abnormal conductivity induced could be near-normalized by attenuating the Kv1.1-mediated currents with $\mathrm{DTX}_{\mathrm{k}}$, a selective and potent blocker of Kv1.1 homomeric channels in the picomolar range (see Table 1$){ }^{16}$ Thus, Kv1.1 is a promising target for extracellular inhibitors to potentially ameliorate such symptoms in demyelinated conditions like MS.

For more information, see the IUPHAR compendium of voltage-gated ion channels (2016): http://www. guidetopharmacology.org/GRAC/ObjectDisplayForward? objectId=538\#ChannelBlockers and http://www.

Received: August 26, 2016

Published: February 22, 2017 
Table 1. A List of Selected Mammalian Kv1.1 Channel Blockers and Their $\mathrm{IC}_{50}$ Values

$\begin{array}{lr}\quad \text { name of the blocker } & \mathrm{IC}_{50} \text { values }(\mu \mathrm{M}) \\ \text { 4-AP } & 89-100^{15} \\ \text { tetraethylammonium } & 30^{17,18} \\ \text { Flecainide } & 209^{17} \\ \text { Diltiazem } & 144^{17} \\ \text { Nifedipine } & 96^{17} \\ \text { Capsaicin } & 29^{17} \\ \text { 8 } & 15 \text { (this study) }^{17} \\ \text { 5,10,15,20-tetrakis 2-([4-tert-butyl benzamido] ethyl } & 13^{19} \\ \quad \text { carbamate) porphyrin } & 0.02^{17} \\ \text { DTX } & 0.00014^{13} \\ \text { MgTX }_{\text {DTX }} & 0.00003-0.0006^{15,16}\end{array}$

guidetopharmacology.org/GRAC/ObjectInteractions DisplayForward objectId $=538 \&$ familyId $=81 \&$ type $=$ Channel\%20blockers\&structures $=y$. Notice that some of these blockers have cross-reactivity with other Kv1 channels.

In search of low molecular weight blockers, a recombinant concatenation technology ${ }^{18,20}$ was utilized to express various Kv1 channel genes as single open-reading frames after transfecting human embryonic kidney (HEK)-293 cells. Such a strategy allows predetermination of not just the combinations of $\alpha$ subunits but also their actual arrangements in the tetrameric channels delivered to the plasmalemma. This is exemplified by the observed fast-inactivation of Kv1.4containing heteromeric channels only when the Kv1.6 $\alpha$ subunit, with its $\mathrm{N}$-terminal inactivation prevention domain, is placed adjacent to Kv1.4, which possesses an $\mathrm{N}$-terminal inactivation ball. ${ }^{18}$ In this way, we established the importance of the stoichiometry and positioning of $\alpha$ subunits for interactions of inhibitory tetra-ethylammonium with Kv1.1- and 1.2containing concatenated tetramers that mimic those in the brain. $^{20,21}$ Herein, channels composed of tandem-linked $\alpha$ subunits were utilized as representative targets for the development of new, small, and selective inhibitors of Kv1.1. To aid their design, a homology model of rat Kv1.1 tetramer was developed for molecular docking based on the crystallographic structure of the mammalian closely related $\mathrm{Kv1.2.}{ }^{22}$ In this regard, it is noteworthy that symmetrically substituted porphyrins bearing alkyl amino groups (cationic-charged at physiological $\mathrm{pH}$ ) can tightly bind a KcsA-Kv1.3 channel. ${ }^{23,24}$ We recently reported that four porphyrin derivatives with different alkyl ammonium side chains (in length and geometry) inhibit Kv1.1 and/or 1.2 channels expressed in mammalian cells. ${ }^{19}$ Now, a new generation based on diaryldi-(2-pyrrolyl) methane (DPM) is described with various substitutions bearing alkyl ammonium side-chains, which have been screened against recombinantly generated $\mathrm{Kvl}$ channels of known subunit

\section{Scheme 1. Synthetic Route Employed to Prepare the DPM-Based $\mathrm{K}^{+}$Channel Inhibitors $6-8^{a}$}

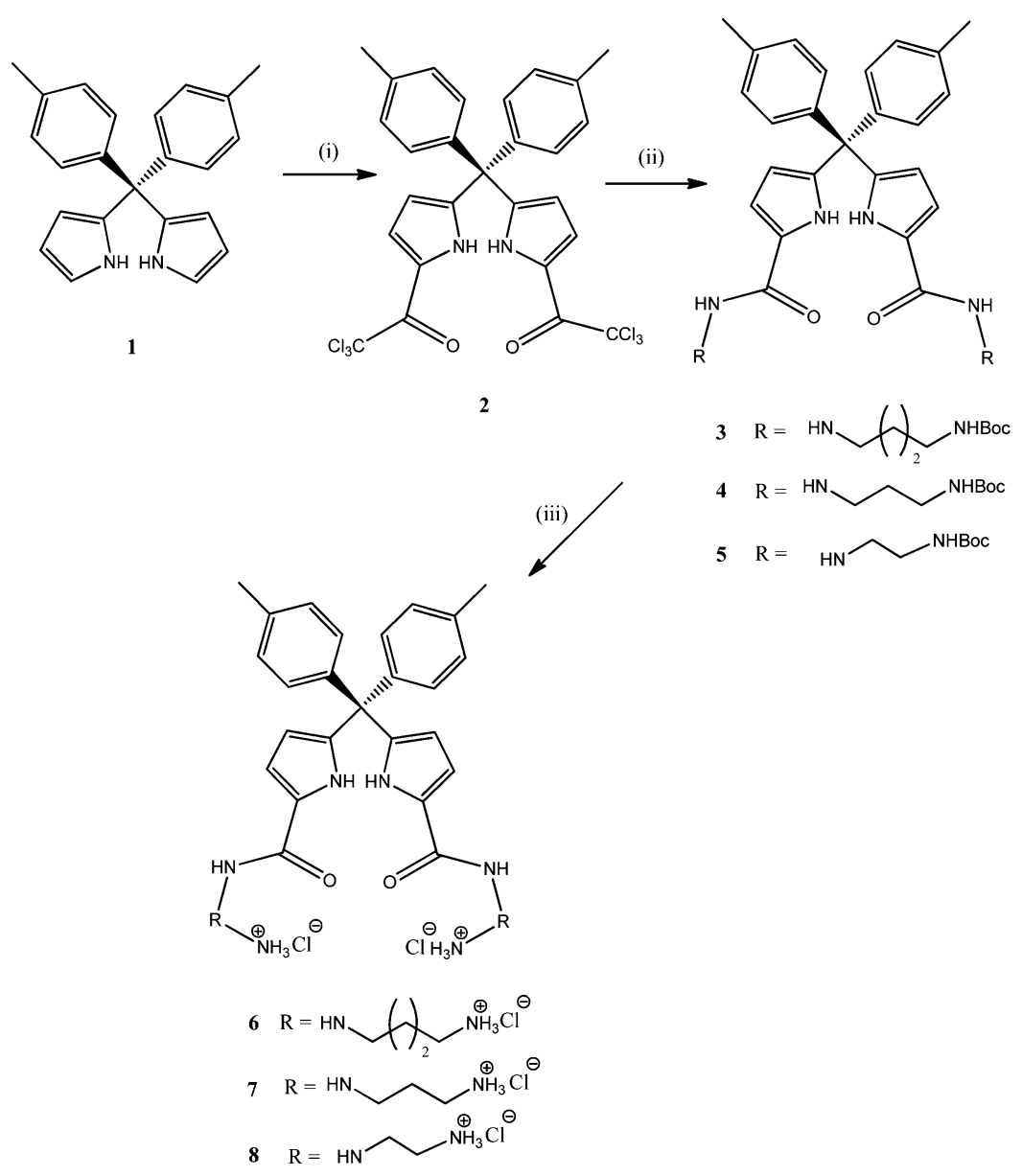

${ }^{a}$ Three steps were used to build the compounds from the DPM scaffold 1: (i) 4-dimethylaminopyridine (DMAP), trichloroacetic acid, dichloromethane (DCM); (ii) N-boc protected diamine, triethylamine (TEA), DCM at room temperature; and (iii) $4 \mathrm{M} \mathrm{HCl}$ in dioxane, DCM. 

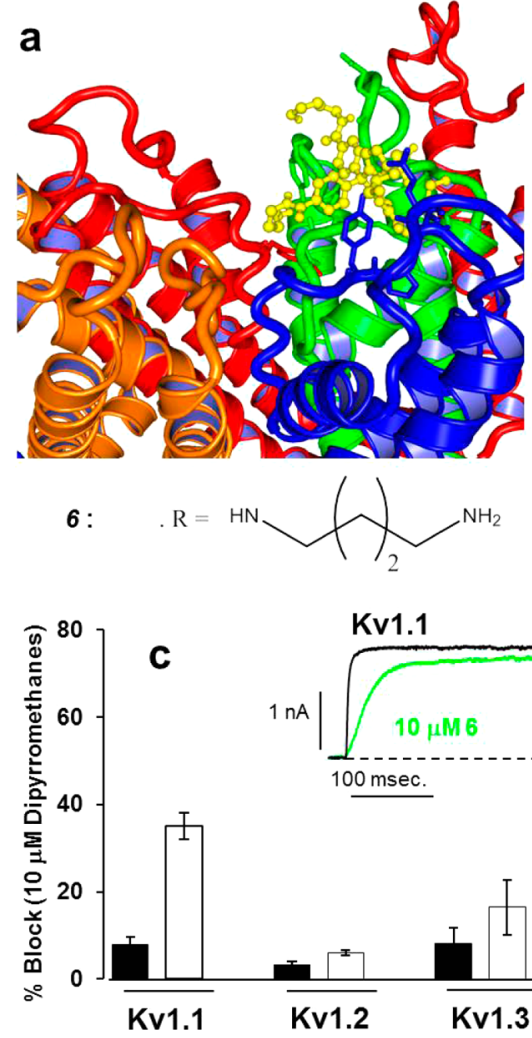

Kv1.1

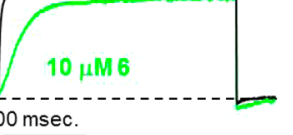

b

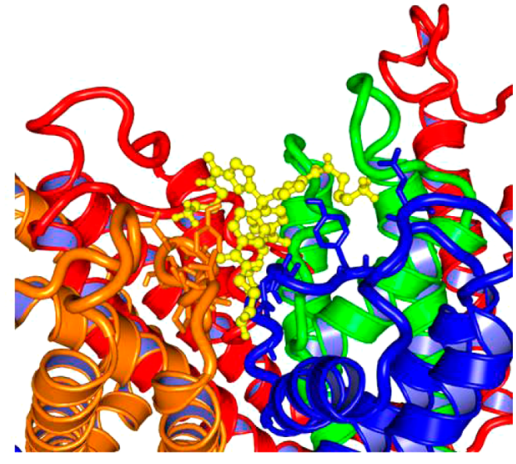

7:

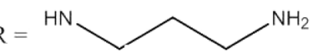

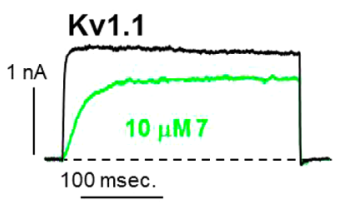

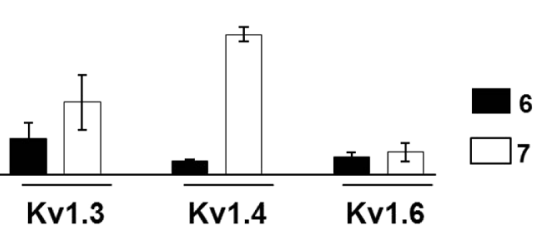

Figure 1. Docking model of the Kv1.1 channel with either of two DPMs. Side views of the docking of 6 (a) and 7 (b) (in yellow) to the extracellular pore region of the Kv1.1 channel. Notice that the former interacts with the outer turret region slightly off-center of the pore, whereas the latter binds more centrally, protruding deep enough to be close to the selectivity filter of Kv1.1. The four Kv1.1 subunits are depicted with red, orange, blue, and green colors for clarification. Images were generated using PyMOL (The PyMOL Molecular Graphics System). Representative electrophysiologically recorded current traces (lower panels) reveal that 6 caused limited inhibition of Kv1.1 and 1.3 [8 $2 \%$ and $8 \pm 3 \%$, respectively ( $n=3)$ ] with even lower reductions of $\mathrm{Kv} 1.2,1.4$, and 1.6 currents $[3 \pm 1 \%, 3 \pm 0.3 \%$, and $4 \pm 1 \%$, respectively $(n=3)]$. More extensive blockade of Kv1.1, 1.3 , and 1.4 was caused by $7[35 \pm 3 \%, 32 \pm 2 \%$, and $16 \pm 6 \%$, respectively $(n=3)]$ with minimal decreases in Kv1.2 and $1.6[6 \pm 1 \%$ and $5 \pm 2 \%$, respectively $(n=3)]$. (c) Histograms show the extents of inhibition of the different Kv1 channels by 6 and 7, revealing the superiority of the latter over the former.

structures. The resultant data were used to design the novel small inhibitor 2,2'-((5,5'-(di-p-topyldiaryldi(2-pyrrolyl)methane) bis $\left(2,2^{\prime}\right.$-carbonyl) bis(azanediyl) )diethaneamine. $2 \mathrm{HCl}(8)$, which proved selective for Kv1.1-containing channels found in rodent demyelinated axons. ${ }^{16}$

\section{RESULTS}

Rational Design of a New Selective Inhibitor for Kv1.1 Channels. In designing selective blockers, their size and hydrophobicity are vital criteria because, if made too small, they would enter deep into the inner pore region, which is conserved in all $\mathrm{K}^{+}$channels and, similar to 4-aminopyridine (4-AP), selectivity would be lost. Although we have reported that various substituted porphyrin derivatives are selective blockers of neuronal Kv1 channels ${ }^{19}$ due to their phototoxicity and high molecular weights, these are nonideal therapeutic candidates. ${ }^{25}$ However, informed by structure-activity relationships of the porphyrins and using molecular modeling, valuable pharmacophore information was realized that afforded the development of a more suitable lead structure. The goal was to rationally design an inhibitor that (1) is large enough to avoid entering the deep inner pore region of the Kvl channels, (2) targets the essential amino acid residues in the vicinity of their selectivity filter/inner turret region, and (3) and lacks absorption in the visible region of the solar spectrum, thereby precluding phototoxicity. The scaffold of the DPM derivatives, outlined in Scheme 1, was modeled using the same homology structure of Kv1.1 as for the porphyrins. Geometric quality of the backbone conformations and energy profiles of the modeled structures fall well within the restrictions established for reliable structures. ${ }^{26-28}$ For refining the side chain of amino acids in the pore region of the Kv1.1 channel, flexible docking was performed with the Autodock protocol. ${ }^{29}$

The alky ammonium side-chains of 2-4 carbon lengths in the tetraphenyl prophyrin scaffold revealed compounds with selective inhibition for currents mediated by Kv1.1 and 1.2 channels. ${ }^{19}$ Encouraged by these outcomes, we introduced these same side-chains into the DPM scaffold to give 6-8, noting that the DPM scaffold represents half the size of a C4tetraphenyl porphyrin and does not absorb visible light.

The predicted interactions of 6 with $\mathrm{Kvl} \alpha$ subunits in the Kv1.1 channel model (Figure 1a) via hydrogen bonds (HB) are Glu353 (two), Asp361 (one), Tyr375 (one), Gly376 (one), Tyr379 (two), Pro380 (one), and Val381 (one). Hydrophobic contacts include Met378 (one) and Tyr379 (one). The modeling showed that the docked molecules interact with the outer region of the channel (Figure 1a), mimicking that of $\mathrm{DTX}_{\mathrm{k}}$, a renowned high-affinity and absolutely specific inhibitor of Kv1.1. ${ }^{16}$ This mechanism of binding differs from the characteristics of 4-AP but can participate in $\mathrm{HB}$ and $\pi-\pi$ stacking interactions. These advantageous features highlight 


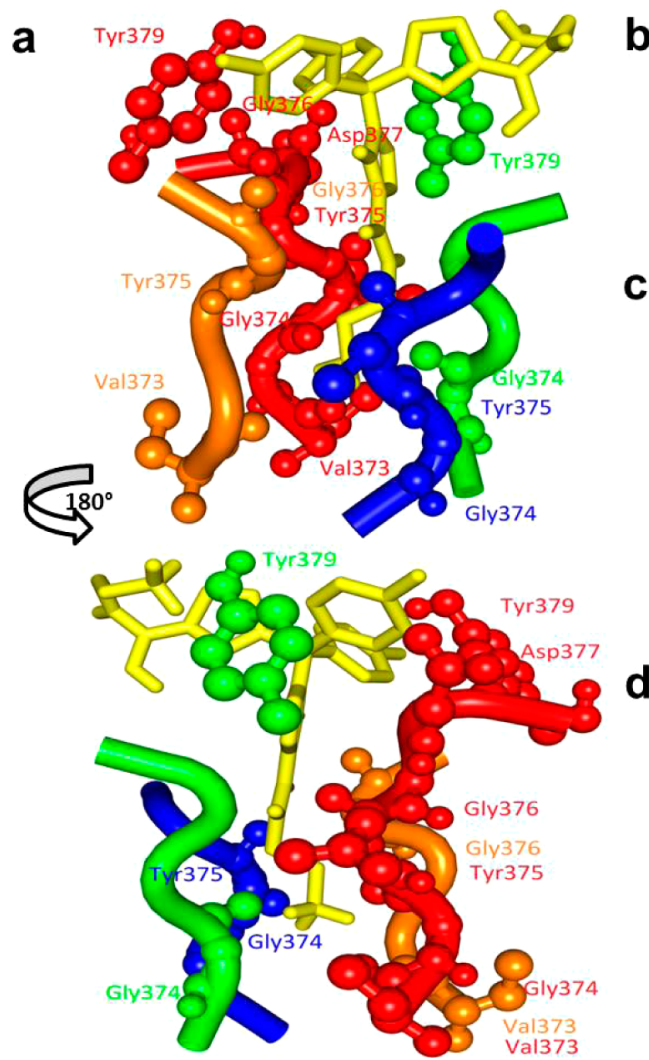

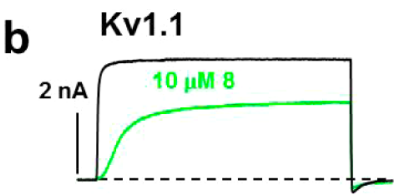

Kv1.2
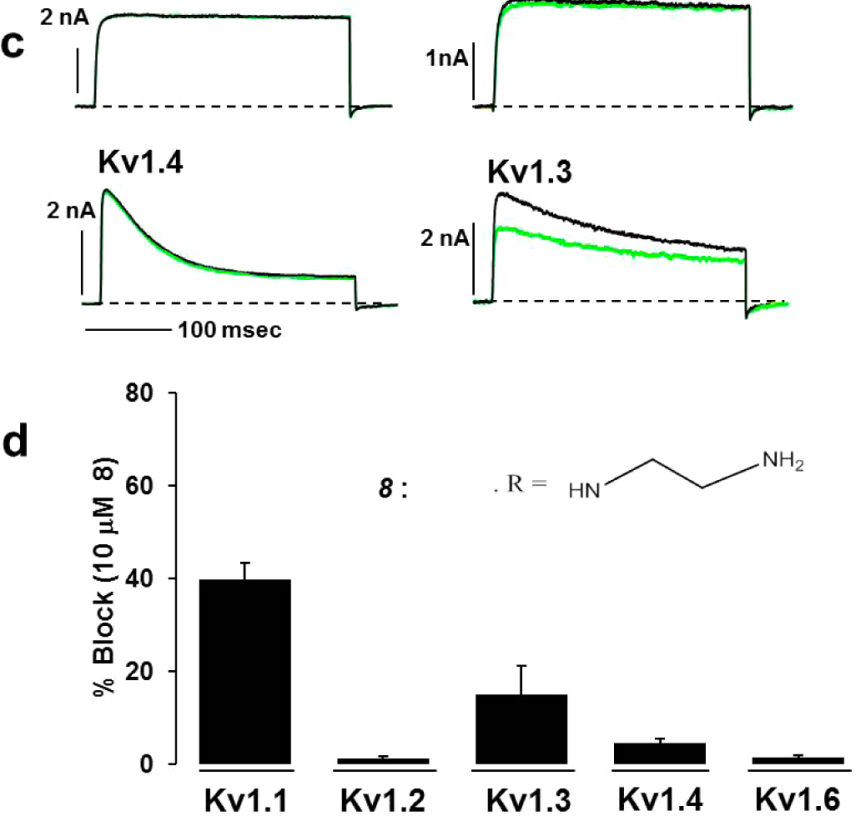

Figure 2. Compound 8 showed preferential selectivity for the Kv1.1 channel. (a) Close-up view illustrating modeling of the docking of 8 (in yellow) with the $\alpha$ subunits of the monomeric Kv1.1 channel. This docking is seen in the upper panel and after horizontal $180^{\circ}$ rotation (bottom panel). Interacting amino acids from each of the four $\alpha$ subunits are represented in orange, red, blue, and green colors. Notice that the interaction of sidechains in 8 are mainly with 2 subunits. Images were generated using PyMOL. (b) Representative current traces from the Kv1.1 channel in the absence (black) and presence (green) of $10 \mu \mathrm{M} 8$ showing inhibition, which was relieved upon washing. Currents were evoked at $20 \mathrm{mV}$ voltage steps from $-90 \mathrm{mV}$ holding potential. (c) Recordings demonstrate a lack of significant effect of 8 on Kv1.2, 1.4, and $1.6[1 \pm 0.5 \%(n=3), 5 \pm 1 \%$ $(n=4)$, and $1 \pm 0.5 \%(n=3)$, respectively] but some inhibition of Kv1.3 [15 $\pm 5 \%(n=3)]$. The histogram confirms the preferential inhibition by 8 of Kv1.1 [40 $\pm 3 \%(n=9)]$ over the other channels tested.

that the DPM scaffold has promise as the basis for a new lead molecule.

Similar channel interactions with the Kv1.1 $\alpha$ subunits were observed for 7 (Figure 1b), i.e., HB with Glu353 (one), Gly374 (all), Tyr375 (two), Gly376 (two), Asp377 (two), Tyr379 (one), Pro380 (one), and Val381 (one). Hydrophobic contacts again involve Tyr379 (two subunits). Hence, both compounds were predicted to contact Glu353 of the outer turret and a range of residues in the inner turret. Moreover, the arm of 7 was expected to be positioned slightly deeper into the inner turret (e.g., making contact with Gly374 of all subunits) than that of 6. Predicted interactions of 8 with Kv1.1 $\alpha$ subunits in the channel (Figure 2a) involve HB with Val373 (two) and Gly374 (three) through the peptide bond, Tyr375 (three), Gly376 (two), Asp377 (two), and Tyr379 (two). Note that these residues reside in the inner pore and include key $\pi-\pi$ stacking interactions with Tyr379 of Kv1.1. Guided by the outcomes from these modeling studies, this new generation of 6-8 was prepared with various substitutions bearing alkyl ammonium side-chains and screened against expressed recombinant $\mathrm{Kvl}$ channels of known subunit structures.

Preparation of 6-8. Their syntheses (Scheme 1) first involved preparing a DPM scaffold by condensation of pyrrole and 4,4-dimethylbenzophenone in the presence of boron trifluorodietherate $[\mathrm{BF} 3(\mathrm{OEt}) 2]$ to yield compound $\mathbf{1}$ in $50 \%$ yield. Introduction of the required carboxyl groups into compound $\mathbf{1}$ at the 2 position of pyrrole was achieved in quantitative yields by electrophilic disubstitution of $\mathbf{1}$ with trichloroacetic anhydride (TClAA) in the presence of a catalyst DMAP to generate compound 2 . The latter was converted to the N-Boc-protected precursors $3-5$ by stirring 2 with the appropriate mono N-Boc-protected alkyl diamine and TEA at room temperature overnight to give compounds 3-5 in quantitative yield without need for further purification. Deprotection of compounds 3-5 was achieved using $4 \mathrm{M}$ $\mathrm{HCl}$ in dioxane to give protonated derivatives 6-8 in quantitative yields. The identity and purity of 6-8 were confirmed by high-resolution mass spectrometry and NMR (given in the Supporting Information). It should be noted that attempts were made to prepare various DPM derivatives containing various substituents in the phenyl groups but that these attempts failed.

Relative Inhibition by 6-8 of Kv1.1- and Kv1.2Containing Channels. For the reactivities of $6-8$ with Kv1 channels to be measured, those containing the major $\alpha$ subunits found in mammalian brain ${ }^{11,14}$ were stably expressed in HEK293 cells, and their $\mathrm{K}^{+}$currents were recorded electrophysiologically using whole-cell voltage patch-clamp. Representative $\mathrm{K}^{+}$current traces, in the absence or presence of 10 $\mu \mathrm{M} 6$ (Scheme 1), revealed limited inhibition of Kv1.1 and 

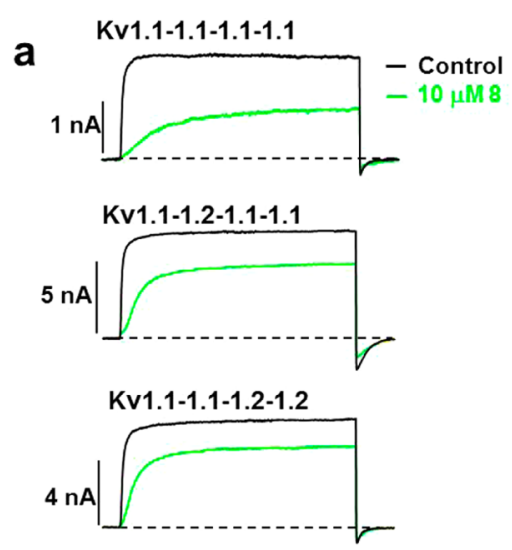

Kv1.2-1.2-1.1-1.2

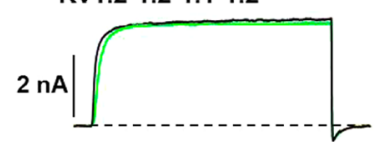

Kv1.2-1.2-1.2-1.2

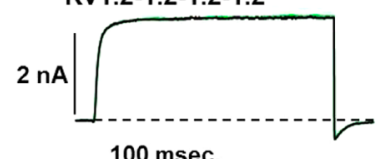

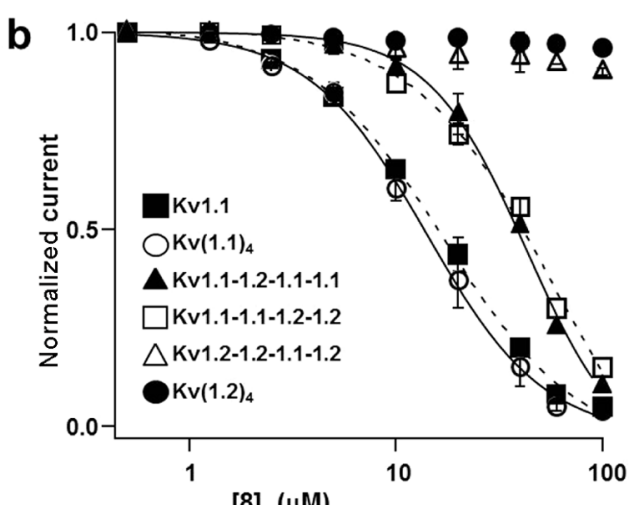

[8] $(\mu \mathrm{M})$

C

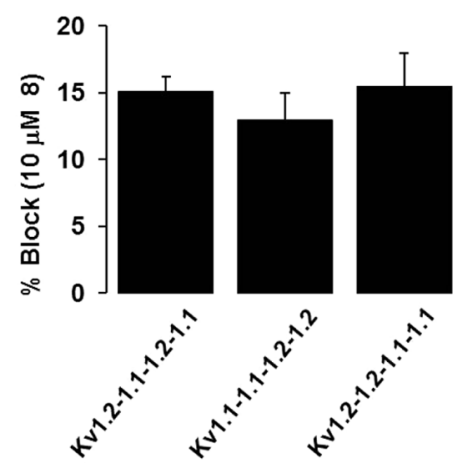

Figure 3. Concatenated Kv1.1-containing channels displaying different sensitivities to 8. (a) Representative current traces from Kv1.1/1.2-containing tetrameric channels in the absence (black) and presence (green) of $10 \mu \mathrm{M} \mathrm{8}$. It partially inhibits those containing 2, 3, or 4 copies of Kv1.2 subunits while proving ineffective against Kv1.2 homotetramer or Kv1.2-1.2-1.1-1.2 channels. (b) Dose-response curves for $\mathrm{Kv}(1.1)_{4}(\mathrm{O})$ and $\mathrm{Kv1.1}(\boldsymbol{\square})$

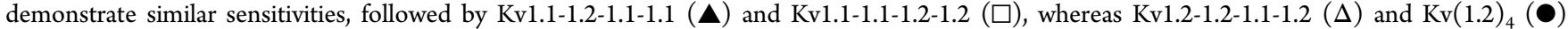
were nonsusceptible. Some of the error bars fall within the data points. $\mathrm{IC}_{50}$ values are summarized in Table 2. (c) Summary of equal inhibition by 8 of tetrameric channels containing two copies of Kv1.1 with different positioning within the concatamers [Kv1.2-1.1-1.2-1.1 = 15 $\pm 1 \%(n=6)$, Kv1.1-1.1-1.2-1.2 = $13 \pm 2 \%(n=4)$, and Kv1.2-1.2-1.1-1.1 = $15 \pm 2 \%(n=5)]$.

Kv1.3 with negligible effects on Kv1.2, 1.4, or 1.6 channels (Figure 1c). Compound 7 (Scheme 1), which possesses a shorter alkyl chain than that of 6 , gave much more inhibition of $\mathrm{Kv} 1.1$ at $10 \mu \mathrm{M}[35 \pm 3 \%(n=3)]$ and a lesser extent for Kv1.3 $[16 \pm 6 \%(\mathrm{n}=3)]$ channels while being ineffective toward Kv1.2 or 1.6 homomers (Figure 1c). Unexpectedly, the Kv1.4mediated current was considerably reduced by $10 \mu \mathrm{M} 7[32 \pm$ $2 \%(n=3)$ ] (Figure 1c).

The final candidate, 8 (Scheme 1), which has the shortest chain, caused a preferential block $[40 \pm 3 \%(n=9)]$ of the Kv1.1 homomeric channel, which could be reversed upon washing (Figure $2 \mathrm{~b}, \mathrm{~d}$ ). Its selectivity was highlighted by the lack of an effect on Kv1.2, 1.4, or 1.6, though some inhibition ( 20\%) of Kv1.3 was apparent (Figure 2c, d). During some recordings in the presence of DPM compounds, HEK cells were subjected to a UV source for less than a minute. No functional damage was detected under such conditions, demonstrating that these do not act as photosensitizers.

Analysis of different heterotetramers of tandem-linked Kv1.1 and 1.2 stably expressed in HEK-293 cells yielded varying susceptibilities to the blocker. Decreasing the copy number of Kv1.1 in those concatamers lowered the extent of inhibition by $10 \mu \mathrm{M} 8$ (Figure 3a): $\mathrm{Kv}(1.1)_{4}>\mathrm{Kv}(1.1)_{3}-1.2=\mathrm{Kv}(1.1)_{2}$ $(1.2)_{2}$ with $\mathrm{Kv}(1.1)-(1.2)_{3}$ and $\mathrm{Kv}(1.2)_{4}$ being insensitive (Figure 3a, b).

The dose-dependencies for blockade revealed that the $\mathrm{IC}_{50}$ values for 8 decreased from $14 \mu \mathrm{M}$ for $\mathrm{Kv}(1.1)_{4}$ to 54 and 57 $\mu \mathrm{M}$ upon introducing one and two copies of Kv1.2 (Table 2).
Table 2. $\mathrm{IC}_{50}$ Values for Inhibition by 8 of Kv1.1 Homomer Compared to Those for Various Concatenated Tetramers of Kv1.1, Kv1.2, and Both ${ }^{a}$

\begin{tabular}{lrrr|}
\multicolumn{1}{c}{ channel } & $\mathrm{IC}_{50}[\mu \mathrm{M}]$ & Hill slope & $N$ \\
$\mathrm{Kv} 1.1$ & $16 \pm 1$ & $1.4 \pm 0.2$ & 8 \\
$\mathrm{Kv}(1.1)_{4}$ & $14 \pm 1$ & $1.5 \pm 0.2$ & 8 \\
$\mathrm{Kv}(1.1)_{3}-1.2$ & $54 \pm 7^{b}$ & $1.5 \pm 0.1$ & 7 \\
$\mathrm{Kv}(1.1)_{2}-(1.2)_{2}$ & $57 \pm 15^{b}$ & $1.3 \pm 0.2$ & 5 \\
$\mathrm{Kv} 1.1-(1.2)_{3}$ & $>100$ & & 6 \\
$\mathrm{Kv}(1.2)_{4}$ & $>100$ & & 4
\end{tabular}

${ }^{a}$ Results are represented as means \pm SEM. ${ }^{b}$ Values are significant compared to $\mathrm{Kv}(1.1)_{4}, P<0.05$, unpaired $t$ test.

Notably, altering the positions of Kv1.1 and 1.2 within the concatamers did not influence their blockade by $10 \mu \mathrm{M} 8$ (Figure 3c). Interestingly, inhibition of Kv1.1 channels by 8 was associated with significant slowing $(\sim 10$-fold $)$ of activation (Figures $3 \mathrm{a}$ and $4 \mathrm{a})$. The time constants $\left(\tau_{\text {activation }}\right)$ for activation of Kv1.1 currents were slowed from $1.9[ \pm 0.15 \mathrm{~ms}$, $(n=4)]$ to $20.3[ \pm 3.3 \mathrm{~ms}(n=4)](p<0.005$, Figure $4 \mathrm{a})$ for the homomer and $2.2[ \pm 0.1 \mathrm{~ms}(n=5)]$ to $19.5[ \pm 3.4 \mathrm{~ms}(n=$ $4)](p<0.001)$ for the Kv1.1 concatamer (data not shown). Likewise, $\tau_{\text {activation }}$ values for the heteromeric channels were increased by $10 \mu \mathrm{M} 8$ for channels in which the number of $\mathrm{Kv} 1.1$ subunits was raised to 2 in $\mathrm{Kv}(1.1)_{2}-(1.2)_{2}$ [ from $2.8 \pm$ $0.4 \mathrm{~ms}(n=6)$ to $18 \pm 2 \mathrm{~ms}(n=5)]$ and 3 in $\mathrm{Kv}(1.1)_{3}-1.2$ [from $3.1 \pm 0.2 \mathrm{~ms}(n=5)$ to $14 \pm 2 \mathrm{~ms}(n=5)]$ derived from the representative current traces shown (Figure 3a). Moreover, 

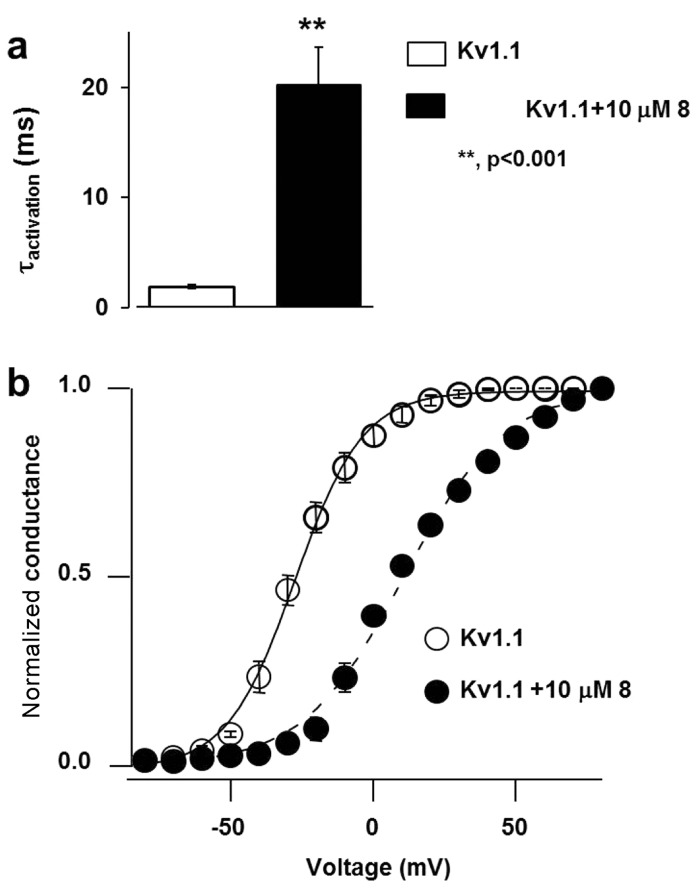

Figure 4. Activation kinetics of the $\mathrm{K}^{+}$current mediated by the Kv1.1 channel are slowed, and the threshold potential is raised by 8 . (a) Time constants of activation $\left(\tau_{\text {activation }}\right)$ for homomeric Kv1.1 before $(\square)$ and after application of $10 \mu \mathrm{M} 8(\boldsymbol{\square})$ determined by fitting the current traces with a monoexponential function. Notice a significant slowing in the time-course of activation [from $1.9 \pm 0.15 \mathrm{~ms}(n=4)$ to $20.3 \pm 3.3 \mathrm{~ms}(n=4) ; p<0.001]$. (b) Conductance-voltage relationship of the steady-state currents for homomeric Kv1.1 (O) showing a significant shift toward more positive potentials induced by 8 (๑) [from $-27 \pm 1 \mathrm{mV}(n=7)$ to $11 \pm 1 \mathrm{mV}(n=4) ; p<0.001$ ]. Some of the error bars fall within the data points.

the $\mathrm{gV}$ relationship of the Kv1.1 channel was altered by $10 \mu \mathrm{M}$ 8 from a half-maximal value for activation $\left(V_{1 / 2}\right)$ of $-27[ \pm 1$ $\mathrm{mV}(n=7)]$ to $11[ \pm 1 \mathrm{mV}(n=4)]$ (Figure $4 \mathrm{~b})$, a significant shift of $\sim 40 \mathrm{mV}$ toward positive potentials. Collectively, these findings unveil notable inhibition by 8 of Kv1-containing $\mathrm{K}^{+}$ channels and compounded modulation of the biophysical properties of Kv1.1.

Compound 8 Raises the Neuronal Excitability of Demyelinated Fibers in Brain Slices. Excitability of demyelinated fibers in the corpus callosum (CC) of cuprizone-treated mice was increased by 8 . Luxol staining revealed that myelination of the $\mathrm{CC}$ from mice fed a cuprizonecontaining diet was substantially reduced (data not shown), consistent with our previous report. ${ }^{16}$ In accordance with the distinct peaks of compound action potentials (cAPs) reported for CC having been attributed to mixed myelinated (N1) and unmyelinated (N2) axons, ${ }^{30,31}$ the cAPs recorded there (Figure $5 \mathrm{a}$ ) show the expected $\mathrm{N} 1$ and $\mathrm{N} 2$ waves (Figure $5 \mathrm{~b}$ ).

The extracellular recordings (Figure 5) of cAPs correspond to the sequential activation of myelinated and unmyelinated fibers (Figure 5b); blockade of both by $\mathrm{TTX}^{30}$ verified their identities (Figure 5b). It is noteworthy that after cuprizone treatment the amplitude of the $\mathrm{N} 1$ wave was drastically reduced whereas that of N2 increased (Figure 5b), consistent with demyelination having occurred. Under control conditions, increasing the electrical stimulus intensity produced an incremental increase in the amplitude of the $\mathrm{N} 2$ wave in all slices from control and cuprizone-treated mice (Figure 5c). A leftward shift of the input/output curve was noted in the cuprizone group as expected for demyelinated fibers (Figure 5c). Moreover, there was a significant increase in the normalized $\mathrm{N} 2$ wave in slices from the cuprizone-treated relative to control animals at stimulus intensities of 2 and $3 \mathrm{~V}$ with $p<0.001$ and 0.01 , respectively, derived from two-way ANOVA test. Initial experiments on control slices showed that neither 8 nor 4-AP exerted any significant effect on the N2 amplitude relative to the baseline (with values for 1 and $10 \mu \mathrm{M}$ 8 being $100.9 \pm 2.8 \%$ and $102.6 \pm 1.9 \%$, respectively, and for 1 and $10 \mu \mathrm{M}$ 4-AP being $105.3 \pm 7.3 \%$ and $105.7 \pm 4 \%$, respectively, with $n=4$ and $\mathrm{df}=3 ; p>0.05$ for all) is consistent with published findings. ${ }^{32}$ On the other hand, in slices from cuprizone-treated mice, $1 \mu \mathrm{M} 8$ slightly increased the amplitude of N2 (Figure $5 \mathrm{~d}$ ), though the difference was not significant from the baseline $[108.2 \pm 4.3 \%(n=6)$ with $t=1.93$ and $\mathrm{df}=$ 5; $p>0.05)$. However, application of $10 \mu \mathrm{M} 8$ increased the amplitude of the N2 significantly relative to the baseline (127.8 $\pm 9 \%$ with $n=6, t=3.10$, and $\mathrm{df}=5 ; p<0.05$ ) (Figure $5 \mathrm{~d}$ ). In the cuprizone-treated animal group, no significant difference was observed in the $\mathrm{N} 2$ amplitude after perfusing the slices with 1 or $10 \mu \mathrm{M} 4-\mathrm{AP}$ when compared to $\mathbf{8}$ (Supporting Figure 2).

\section{DISCUSSION}

These data show that 8 interacts with at least two Kv1.1 subunits in heteromeric channels and that the effect becomes accentuated by increasing their number. Molecular modeling of the porphyrins ${ }^{19}$ yielded valuable pharmacophore information on their channel binding affinities, especially the types of interactions that could be crucial for inhibition of Kv1.1. The resultant data on the porphyrins suggested that the lack of selectivity for particular channel subtypes could arise from the large number of interactions with conserved residues present in all Kv1 channels. As a first consideration of the necessary selectivity for Kv1.1 channels, the size of the scaffold to which the side arm alkyl ammonium groups are attached needed to be reduced. Rational drug design for many voltage-gated ion channels has been hampered by a paucity of adequate crystal structures and the challenge of achieving inhibitors exhibiting subtype selectivity. In this work, a successful combination of synthetic chemistry, molecular modeling, and electrophysiology have led to 8, a DPM molecule bearing two C2-alkyl ammonium side-chains.

The specific alignment of the backbone residues in the selectivity filter region of $\mathrm{Kvl}$ channels is essential for their conductance. As previously reported by Ader et al., conformational alterations occurring in the HB network of the selectivity filter have a direct influence on $\mathrm{K}^{+}$current gating. ${ }^{23}$ The residues that are located in this region are Val373, Gly374, Tyr375, Gly376, and Asp377. A logical design of 6-8 was undertaken, and the derivatives were assembled with the aid of molecular docking to disrupt the HB network of these residues deep in the pore. Residue Tyr379 in the inner turret region of Kv1.1 was a key interaction to target due to its distinction from the other Kv1 channels (e.g., Val in Kv1.2, His in Kv1.3, Lys in $\mathrm{Kv1.4}$, and Tyr in Kv1.6). Interestingly, the His in Kv1.3 may play a similar role in ligand binding to Tyr 379 of Kv1.1, partially explaining the level of inhibition by 7 and $\mathbf{8}$ compared to those of other Kv1 subtypes. Compound 8, which exhibited the best selectivity of the three compounds screened, possesses groups with the potential to create $\mathrm{HB}$, salt bridges, and $\pi-\pi$ stacking between the residues of interest. Compound $\mathbf{8}$ (Figure $2 a)$ binds to the outer region of the channel with its reactive 

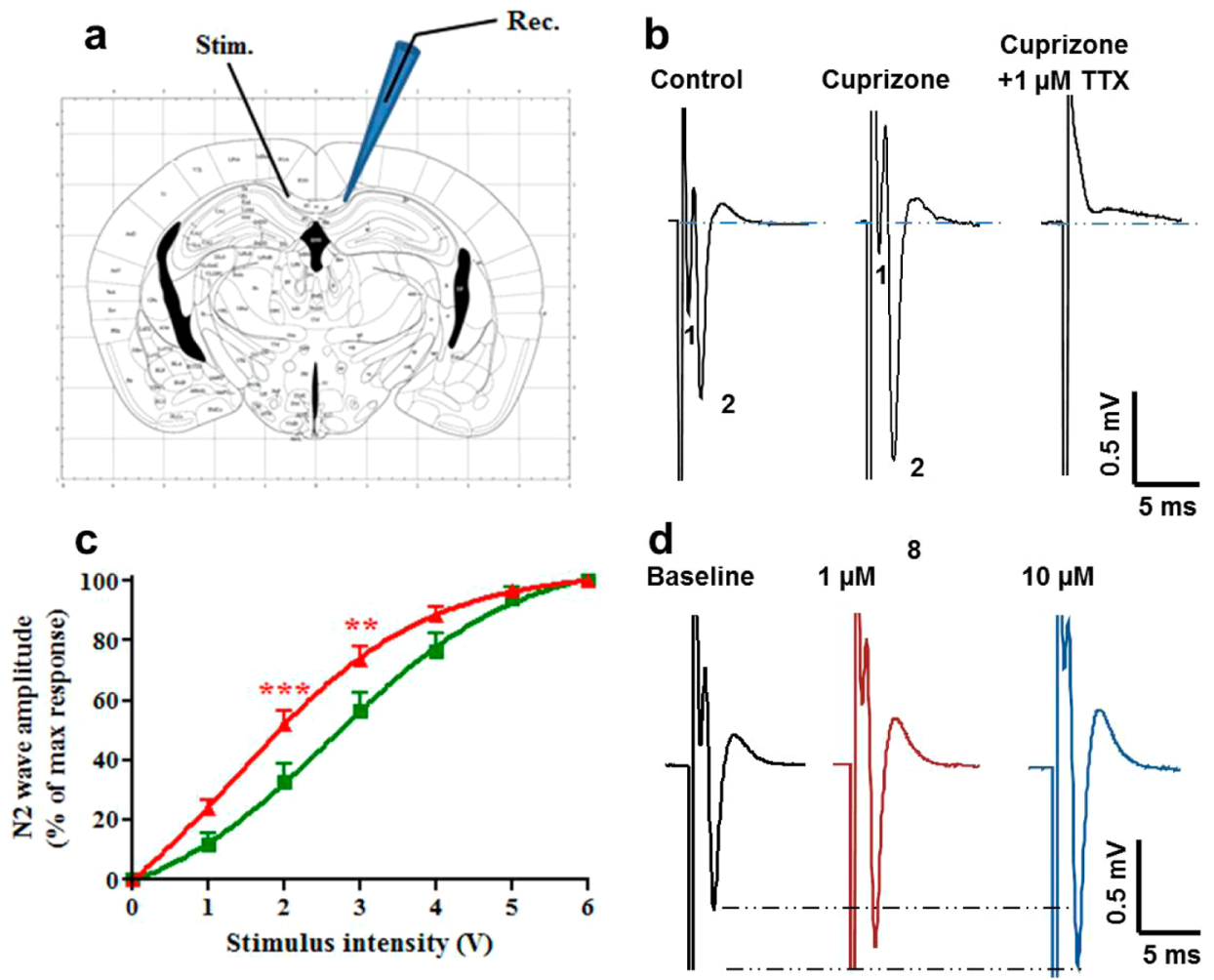

Figure 5. Compound 8 improves the excitability of demyelinated fibers in CC slices of mice fed a diet containing cuprizone. (a) Schematic showing the positioning of stimulating and recording electrodes in a brain coronal slice to record CC cAPs. (b) Examples of cAPs recorded in slices from control and cuprizone-treated mice. The myelinated N1 (1) and the unmyelinated N2 (2) waves of the CC cAPs are shown. Tetradotoxin (TTX) sensitivity of cAPs was recorded in the same slice taken from a cuprizone-treated mouse. (c) The I/O curve shifted to the left in slices taken from cuprizone-treated mice $(n=6$ mice, red curve) when compared to control animals $(n=4$ mice, green curve). $* *$ and $* * *$ indicate significant differences when comparing cuprizone-treated group vs control group. (d) Representative recordings of cAPs in the same slice from cuprizonetreated mice before (baseline) and the increase in excitation (dashed lines) after application for $10 \mathrm{~min}$ of 1 and $10 \mu \mathrm{M} 8$ (a significant difference is seen between the dashed lines, $p<0.05)$.

groups reaching the pore. This is the type of binding that is required to mimic the striking specification of $\mathrm{DTX}_{\mathrm{k}}$, establishing that this scaffold is a promising constituent for new lead molecules. Although predominant cardiac Kv channels, such as Kv1.5 and hERG, were not tested, the pore alignment of these channels with Kv1 members indicates that 8 might not interact with these channels (see Supporting Figure 1). The key residue (Tyr379) of Kv1.1 is replaced by Ser431 in hERG channel (in addition to other dissimilar residues at the selectivity filter region) and Arg489 in Kv1.5 channels. These findings support the notion that $\mathbf{8}$ should not exert adverse effects on cardiac function. Furthermore, Kv2.1 gives residue alignment similar to that of Kv1.2 at the outer turret region but with a unique residue difference at the key location (Thr380, see Supporting Figure 1); hence, no inhibition is expected of the Kv2.1 channel by 8 .

The functional properties of $\mathbf{8}$, measured electrophysiologically, are in accordance with those predicted from in silico analysis. This compound is devoid of reactivity with Kv1.2, 1.4, and 1.6 channels and preferentially inhibits Kv1.1 but with less blockade of the 1.3 channel. Evaluation of this promising molecule on Kv1.1/1.2-heteromeric channels was possible by utilizing a cloning strategy that affords expression of four $\alpha$ subunits as single-chain proteins on the plasmalemma with the compositions and positions of their subunits predetermined. ${ }^{20,21}$ Tetrameric combinations that should correspond to those predicted to occur in brain ${ }^{11,14}$ were selected for investigation, including those Kv1.1-enriched channels ob- served in demyelinated axons. ${ }^{16}$ Selectivity of $\mathbf{8}$ for inhibiting the Kv1.1 channel arise in large part from acting extracellularly, namely, with the outer turret regions of Kv1.1 before occluding the channel deep in its vestibule. This explains its limited crossreactivity with Kv1.3, which has accessible serines closely resembling those lining the outer turret of Kv1.1 and only one residue difference (His404, see Supporting Figure 1) at the key location. ${ }^{19}$ For comparison, 5,10,15,20-tetrakis 2-([4-tert-butyl benzamido] ethyl carbamate) porphyrin bearing similar alkyl ammonium side chains to that of $\mathbf{8}$ was selective in blocking Kv1.1 and 1.4, ${ }^{19}$ two subunits predominantly present in CNS, with $\mathrm{IC}_{50}$ values of 13 and $21 \mu \mathrm{M}$, respectively. ${ }^{16}$ Advantageously, 8 shows an equivalent inhibition of Kv1.1 but lacks reactivity toward Kv1.4. On the other hand, Kv1.1 and 1.2 channels share similarly low susceptibility to 4-AP due to their conserved inner vestibule region where it interacts. ${ }^{8,33}$ Furthermore, the selective inhibition and slowing of activation kinetics of the Kv1.1 channel highlight the dual advantages of 8 . In comparison, the above-mentioned pophyrin also showed this dual effect toward the Kv1.1 channel but induced a smaller modification of the activation kinetics. ${ }^{19}$ Bagchi et al. demonstrated that in demyelinated axons of mouse optic nerve an increase in ectopic expression of the Kv1.1 subunit contributes to abnormal cAPs. ${ }^{16}$ These cAPs decrease the voltage threshold (activated at more negative potentials) and accelerate the activation kinetics, thereby perturbing the axonal propagation of electrical signals; accordingly, it was found that this dysfunction can be partially overcome by the Kv1.1- 
selective inhibitor $\mathrm{DTX}_{\mathrm{k}}{ }^{16}$ Although such an avid toxin cannot be considered as a potential neurotherapeutic, its beneficial effects in vitro warranted the development of more suitable smaller inhibitors. Thus, it is encouraging that $\mathbf{8}$ offers a double advantage in preferentially inhibiting Kv1.1-dependent currents, including slowing of their activation and shifting the conductance-voltage relationship of Kvl.1 to more positive potentials. Such a beneficial modulatory action could underly its observed normalization of the cAPs in demyelinated axons, a discovery of relevance to pathophysiology of MS (see below). Its effect on the activation kinetics could be explained by interaction deep in the pore region of Kv1.1 channels. These interactions are in the vicinity of a similar inner-pore region found in the Kv7.2 channel, which can be blocked by $(E)-N$ [(S)-1-(4-cyclopropylmethyl-3,4-dihydro-2H-1,4-benzoxazin-6yl)-ethyl]-3-(2-fluoro-phenyl)- $N$-methylacrylamide, and its activation kinetics slowed. ${ }^{34}$ Experiments on mutants of the Kv7.2 channel revealed that the methyl group on the amide nitrogen of the above-noted blocker binds within the "retigabine binding site". This inner pocket of the channel was shown to interact with components of the selectivity filter in an open state manner, and this leads to slowing of the channels' activation kinetics. ${ }^{35}$ A similar mechanism might apply to 8; however, further work would have to be done to clarify this notion. Furthermore, $\mathbf{8}$ is an extracellular blocker impermeable to intact cell membranes (measured $\log \mathrm{P}$ value of -1.05 , which is highly unfavorable for membrane diffusion) that can distinguish between Kv1.1 and the much more prevalent 1.2 channels. In contrast, the internal blocker 4-AP is readily membrane permeable, interacts with both Kv1.1 and 1.2 channels with similar potency, and can cross the blood-brain barrier. In summary, $\mathbf{8}$ advantageously exhibits a dual action in selectively inhibiting $\mathrm{K}^{+}$currents, which would be expected to reduce the unwanted hyperpolarization caused by homomeric Kv1.1- and Kv1.1-containing channels found to be enriched after demyelination of optic nerve axons. ${ }^{16}$

As lesions in the CC occur in over $90 \%$ of MS cases, ${ }^{36}$ this is a pertinent structure for studying demyelination and its functional consequences. cAP recordings in the $\mathrm{CC}$ revealed two downward phases ( $\mathrm{N} 1$ and $\mathrm{N} 2$ ) corresponding to activation of the myelinated and unmyelinated axons. ${ }^{30,31}$ Both components were abolished by TTX (see Figure 5b). In the cuprizone-treated group, the amplitude of the N1 wave was lower with the N2 magnitude being greater. Similarly, the observed leftwards shift of the input/output curve for the amplitude of the $\mathrm{N} 2$ wave in slices from the experimental mice indicates that the relative number of unmyelinated fibers had increased. In animal models of demyelination, it is known that demyelinated/dysmyelinated axons become initially exposed and that lateral diffusion of juxta-paranodal and nodal voltagegated ion channels can extend into the formerly myelinated internodal regions. ${ }^{32,37}$ Such reorganization partially contributes to the loss of saltatory conduction and slowing of action potential propagation in white matter axons. ${ }^{38}$ In addition, after cuprizone-induced demyelination, we observed in earlier work that Kv1.1 makes a more prominent contribution than Kv1.2 subunits in regulating the excitability and conductivity of the optic nerve. ${ }^{16}$ It is noteworthy that Kv1.1 and 1.2 channels are abundantly expressed in the CC of mice, ${ }^{39}$ activate at potentials near the threshold for action potential generation, and are known to regulate firing patterns in various regions of the CNS. ${ }^{40}$ Herein, the new specific Kv1.1 blocker developed was found electrophysiologically to have an $\mathrm{IC}_{50}$ several times lower than that of $4-\mathrm{AP}^{15}$ (see Table 1). As our results also established that 8 increases the $\mathrm{N} 2$ amplitude in slices from cuprizone-treated mice, it may trigger the activation of other channels and elevate the overall excitability of the demyelinated fibers in the CC through inhibition of Kv1.1; this could offer a substantial advantage for ameliorating the symptomatic phase of MS. The supporting data from the in vitro recording of selected Kv1.1 currents, with its limited data acquisition in comparasion with the high pulse-frequency of the cAP recordings, showed that $\mathbf{8}$ inhibition of Kv1.1 current, a dominant component of $\mathrm{Kv}$ currents, leads to an excitation of demyelinated nerves that would be therapeutically desirable.

Despite its therapeutic use, 4-AP treatment causes many side effects from nausea to paraesthesia ${ }^{41}$ as well as being a potent convulsant; therefore, its utilization in patients is limited. Unlike 4-AP, 8 is a more specific and potent blocker of recombinant Kv1.1 and devoid of the effect on Kv1.2. As the inflammatory component in MS pathophysiology is of prime importance, the noted inhibition of Kv1.3 by 8 might have an additional beneficial effect because this channel is known to activate $\mathrm{T}$ cells and is highly expressed in the inflammatory infiltrates in MS; moreover, Kv1.3 is a functional marker of activated effector memory $\mathrm{T}$ cells in experimental allergic encephalomyelitis and in myelin-specific $\mathrm{T}$ cells derived from the peripheral blood of MS patients.

\section{CONCLUSIONS}

In summary, a newly designed small inhibitor, $\mathbf{8}$, is proven to be selective for Kv1.1-containing channels found in rodent demyelinated axons. ${ }^{16}$ Furthermore, cAP recordings in CC taken from cuprizone-treated mice revealed that this novel compound increases the excitability of the demyelinated fibers. Hence, 8 could have therapeutic potential for the symptomatic phase of MS.

\section{EXPERIMENTAL SECTION}

Computational Methods. The crystal structure of the rat Kv1.2 channel (PDB ID: 2A79) has previously been used as a template for building homology models of $\mathrm{Kvl}$ homotetramers and heterotetramers. ${ }^{23,42-47}$ Protein structures were downloaded from the protein databank (www.rcsb.org). Accelrys Discovery Studio 3.5 was used to prepare the protein structures (add missing atoms, correct connectivity, correct names, etc.) For ligands, we employed Accelrys Discovery Studio 3.5 to enumerate tautomers, stereoisomers, and conformations.

Homology Modeling. In the case of the rat Kv1.1 channel, a homology model was developed and validated as previously described. ${ }^{19}$ In brief, the protein sequence for Kv1.1 was aligned to the template of the known structure (PDB ID: 2A79) using Accelrys Discovery Studio 3.5, and 100 protein structures were built for the selected alignment. The best model was selected using a combination of the Modeler discrete optimized protein energy (DOPE) score and a collection of protein assessment tools. ${ }^{26-28}$ Tetramer models were developed using PyMOL and the biological assembly of the Kv1.1/1.2 channel structures.

Molecular Docking. AutoDock 4, based on a Lamarckian genetic algorithm method, was utilized for molecular docking. ${ }^{48,49}$ Ligands were allowed to be flexible, and flexible residues for the protein were defined as residues $375-381$ in each monomer. ${ }^{19}$ A cubic grid of 140 $\AA \times 140 \AA \times 140 \AA$ around the ion pore was constructed using the Autogrid program with a grid point step of $0.375 \AA$. Default parameters were implemented in Autodock4 with 50 docking runs, and ga_num_evals was set to $25,000,000$ and ga_num_generations fixed at 27,000 . To generate input files, the AutoDockTools program 
was used. ${ }^{29}$ The conformations showing a lower free energy of binding for each ligand were further analyzed.

Synthesis of 1-8. Di-p-tolyldi(2-pyrrolyl)methane (1). A $250 \mathrm{~mL}$ 2-necked round bottomed flask was charged with $1.31 \mathrm{~g}$ of $4,4^{\prime}$ dimethylbenzophenone $(6.18 \mathrm{mmol})$. Anhydrous methanol $(50 \mathrm{~mL})$ was added, and the mixture was magnetically stirred under an argon atmosphere. When the $4,4^{\prime}$-dimethylbenzophenone was fully dissolved, freshly distilled pyrrole $(1.07 \mathrm{~mL}, 15.5 \mathrm{mmol})$ was added dropwise. After $5 \mathrm{~min}, \mathrm{BF} 3 \cdot(\mathrm{OEt}) 2$ was added $(1.07 \mathrm{~mL}, 8.6 \mathrm{mmol})$, and the reaction mixture was allowed to stir for 5 days at room temperature. The precipitate formed was filtered and washed with cold methanol to give a white solid $(1.01 \mathrm{~g}, 50 \%$ yield $)$.

${ }^{1} \mathrm{H}$ NMR (400 MHz, DMSO- $\left.d_{6}\right) \delta 10.2(2 \mathrm{H}$, s, pyrrole-NH), 7.1 $(2 \mathrm{H}$, d, phenyl- $\mathrm{H}), 6.8(2 \mathrm{H}, \mathrm{s}$, phenyl- $\mathrm{H}), 6.7(2 \mathrm{H}, \mathrm{m}$, pyrrole- $\mathrm{H}), 5.9$ $(2 \mathrm{H}, \mathrm{m}$, pyrrole- $\mathrm{H}), 5.6(2 \mathrm{H}, \mathrm{m}$, pyrrole- $\mathrm{H}), 2.3\left(6 \mathrm{H}, \mathrm{s}\right.$, tolyl- $\left.\mathrm{CH}_{3}\right)$. ${ }^{13} \mathrm{C}$ NMR (100 MHz, DMSO- $\left.d_{6}\right) \delta 143.6,135.7,135.1,129.0,127.8$, 117.9, 108.7, 105.9, 54.7, 20.3.

5,5'-(Di-p-tolyldipyrromethane)bis(2-trichlorocarbonyl) (2). To a $25 \mathrm{~mL}$ 2-neck round bottomed flask were added $336 \mathrm{mg}$ of 1 (1 $\mathrm{mmol})$ and $24 \mathrm{mg}$ of DMAP $(0.2 \mathrm{mmol})$, which were stirred and placed under an argon atmosphere. Anhydrous DCM $(10 \mathrm{~mL})$ was then added, and the mixture was cooled to $0{ }^{\circ} \mathrm{C}$. To the stirring solution was added trichloroacetic anhydride $(457 \mu \mathrm{L}, 2.5 \mathrm{mmol})$ dropwise, and the reaction was allowed to stir for an additional $2 \mathrm{~h}$ at room temperature. Then, the reaction mixture was transferred to a small separating funnel, and the organic phase was washed twice $(2 \times$ $10 \mathrm{~mL}$ of water) followed by $(2 \times 10 \mathrm{~mL}) \mathrm{NaHCO}_{3}$ and dried over $\mathrm{MgSO}_{4}$. The DCM was removed to give 2 as a white solid in quantitative yield.

${ }^{1} \mathrm{H}$ NMR (400 MHz, DMSO- $\left.d_{6}\right) \delta 12.1$ (2H, s, pyrrole-NH), 7.29 $(2 \mathrm{H}, \mathrm{d}$, pyrrole- $\mathrm{H}), 7.28(2 \mathrm{H}, \mathrm{d}$, phenyl- $\mathrm{H}), 6.9(2 \mathrm{H}, \mathrm{d}$, phenyl- $\mathrm{H}), 6.1$ $(2 \mathrm{H}, \mathrm{m}$, pyrrole- $\mathrm{H}), 2.3\left(6 \mathrm{H}, \mathrm{s}\right.$, tolyl- $\left.\mathrm{CH}_{3}\right) .{ }^{13} \mathrm{C} \mathrm{NMR}(100 \mathrm{MHz}$, DMSO- $\left.d_{6}\right) \delta 171.8,145.8,140.4,136.4,129.0,128.5,122.5,120.8$, 113.9, 95.2, 55.9, 20.3.

General Procedure for Preparing N-Boc-Protected DPM from Compounds $3 \mathbf{- 5}$. To a $50 \mathrm{~mL}$ round-bottom flask were added $400 \mathrm{mg}(0.65 \mathrm{mmol})$ of 2 into $5 \mathrm{~mL}$ of DCM, and the mixture was allowed to stir for $5 \mathrm{~min}$ at room temperature under an argon atmosphere. N-Boc ethylenediamine $(250 \mu \mathrm{L} ; 1.6 \mathrm{mmol})$ was then added to the mixture followed by the dropwise addition of anhydrous triethylamine $(360 \mu \mathrm{L}, 2.6 \mathrm{mmol})$. The reaction was stirred at room temperature overnight; the resultant precipitate was collected by suction filteration and washed twice with $25 \mathrm{~mL}$ aliquots of DCM before being dried under vacuum to give the N-Boc derivatives in quantitative yield.

Di-tert-butyl (((5,5'-(Di-p-tolyldiaryldi(2-pyrrolyl)methane)bis$\left(2,2^{\prime}\right.$-carbonyl)) bis(azanediyl))bis(butane-4,1-diyl))dicarbamate (3). The general procedure was used with $400 \mathrm{mg}(0.65 \mathrm{mmol})$ of 2 and $290 \mu \mathrm{L}(1.6 \mathrm{mmol})$ of N-boc 1,4-butanediamine to give 3 in quantitative yield.

${ }^{1} \mathrm{H}$ NMR (400 MHz, DMSO- $\left.d_{6}\right) \delta 10.7$ (2H, s, pyrrole-NH), 8.0 $(2 \mathrm{H}, \mathrm{t}, J=5.6 \mathrm{~Hz}$, amide- $\mathrm{NH}), 7.1(4 \mathrm{H}, \mathrm{d}, J=8.0 \mathrm{~Hz}$, phenyl- $\mathrm{H}), 6.8$ $(4 \mathrm{H}, \mathrm{t}, J=8.0 \mathrm{~Hz}$, phenyl- $\mathrm{H}+2 \mathrm{H}$ amide- $\mathrm{NH}$ overlapping $), 6.6(2 \mathrm{H}, \mathrm{d}$, $J=3.6 \mathrm{~Hz}$, pyrrole- $\mathrm{H}), 5.6(2 \mathrm{H}, \mathrm{d}, J=3.6 \mathrm{~Hz}$, pyrrole- $\mathrm{H}), 3.2(4 \mathrm{H}, \mathrm{q}, J$ $\left.=6.0 \mathrm{~Hz}, \mathrm{CH}_{2}\right), 2.9\left(4 \mathrm{H}, \mathrm{q}, J=6.0 \mathrm{~Hz}, \mathrm{CH}_{2}\right), 2.3\left(6 \mathrm{H}, \mathrm{s}\right.$, tol- $\left.\mathrm{CH}_{3}\right)$, $1.41\left(8 \mathrm{H}, \mathrm{m}, \mathrm{CH}_{2}\right), 1.4\left(18 \mathrm{H}, \mathrm{s}\right.$, Boc- $\left.\mathrm{CH}_{3}\right) .{ }^{13} \mathrm{C}$ NMR $(100 \mathrm{MHz}$, DMSO-d $d_{6} \delta 160.3,155.7,142.0,138.7,135.9,129.2,128.2,127.1$, 110.8, 109.7, 77.4, 55.2, 55.0, 39.4, 38.3, 28.3, 27.2, 26.9, 20.6.

Di-tert-butyl (((5,5'-(Di-p-tolyldiaryldi(2-pyrrolyl)methane)bis$\left(2,2^{\prime}\right.$-carbonyl))bis(azanediyl))bis(propane-3,1-diyl))dicarbamate (4). The general procedure was used with $400 \mathrm{mg}(0.65 \mathrm{mmol})$ of 2 and $270 \mu \mathrm{L}(1.6 \mathrm{mmol})$ of $\mathrm{N}$-boc 1,3-propanediamine to give 4 in quantitative yield.

${ }^{1} \mathrm{H}$ NMR (400 MHz, DMSO- $\left.d_{6}\right) \delta 10.8(2 \mathrm{H}, \mathrm{s}$, pyrrole-NH), 8.0 $(2 \mathrm{H}, \mathrm{t}, J=5.3 \mathrm{~Hz}$, amide-NH), $7.1(4 \mathrm{H}, \mathrm{d}, J=8.2 \mathrm{~Hz}$, phenyl- $\mathrm{H}), 6.8$ $(4 \mathrm{H}, \mathrm{t}, J=8.2 \mathrm{~Hz}$, phenyl- $\mathrm{H}+(2 \mathrm{H})$ amide- $\mathrm{NH}$ overlapping $), 6.6(2 \mathrm{H}$, d, $J=3.6 \mathrm{~Hz}$, pyrrole- $\mathrm{H}), 5.7(2 \mathrm{H}, \mathrm{d}, J=3.6 \mathrm{~Hz}$, pyrrole- $\mathrm{H}), 3.2(4 \mathrm{H}$, $\left.\mathrm{q}, J=6.4 \mathrm{~Hz}, \mathrm{CH}_{2}\right), 2.9\left(4 \mathrm{H}, \mathrm{q}, J=6.4 \mathrm{~Hz}, \mathrm{CH}_{2}\right), 2.3\left(6 \mathrm{H}, \mathrm{s}\right.$, tol- $\left.-\mathrm{CH}_{3}\right)$, $1.6\left(4 \mathrm{H}, \mathrm{p}, \mathrm{CH}_{2}\right), 1.4\left(18 \mathrm{H}, \mathrm{s}, \mathrm{Boc}-\mathrm{CH}_{3}\right) .{ }^{13} \mathrm{C}$ NMR $(100 \mathrm{MHz}$,
DMSO- $\left.d_{6}\right) \delta 160.4,155.6,141.9,138.7,135.9,129.2,128.2,126.9$, 110.8, 109.7, 77.5, 55.2, 54.9, 37.7, 36.2, 29.9, 28.3, 20.6.

Di-tert-butyl (((5,5'-(Di-p-tolyldiaryldi(2-pyrrolyl)methane)bis$\left(2,2^{\prime}\right.$ carbonyl))bis(azanediyl))bis(ethane-2,1-diyl))dicarbamate (5). The general procedure was used with $400 \mathrm{mg}(0.65 \mathrm{mmol})$ of 2 and $257 \mu \mathrm{L}(1.6 \mathrm{mmol})$ of $\mathrm{N}$-boc 1,2-ethaneanediamine to give 5 in quantitative yield.

${ }^{1} \mathrm{H}$ NMR (400 MHz, DMSO- $\left.d_{6}\right) \delta 10.8$ (2H, s, pyrrole-NH), 8.0 $(2 \mathrm{H}, \mathrm{t}, J=5.3 \mathrm{~Hz}$, amide- $\mathrm{NH}), 7.1(4 \mathrm{H}, \mathrm{d}, J=8.2 \mathrm{~Hz}$, phenyl-H), 6.9 $(2 \mathrm{H}, \mathrm{m}$, amide- $\mathrm{NH}), 6.8(4 \mathrm{H}, \mathrm{d}, J=8.2 \mathrm{~Hz}$, phenyl- $\mathrm{H}), 6.4(2 \mathrm{H}, \mathrm{d}, J=$ $3.3 \mathrm{~Hz}$, pyrrole- $\mathrm{H}), 5.7(2 \mathrm{H}, \mathrm{d}, J=3.3 \mathrm{~Hz}$, pyrrole- $\mathrm{H}), 3.2(4 \mathrm{H}, \mathrm{q}, J=$ $\left.6.0 \mathrm{~Hz}, \mathrm{CH}_{2}\right), 3.0\left(4 \mathrm{H}, \mathrm{q}, J=6.0 \mathrm{~Hz}, \mathrm{CH}_{2}\right), 2.3\left(6 \mathrm{H}, \mathrm{s}\right.$, tol- $\left.\mathrm{CH}_{3}\right), 1.4$ $\left(18 \mathrm{H}, \mathrm{s}, \mathrm{Boc}-\mathrm{CH}_{3}\right) .{ }^{13} \mathrm{C}$ NMR $\left(100 \mathrm{MHz}, \mathrm{DMSO}-d_{6}\right) \delta 160.6,155.7$, $141.9,138.9,135.9,129.2,128.2,126.9,110.9,109.9,77.7,55.2,54.9$, 39.5, 38.7, 28.3, 20.6.

General Procedure for the Deprotection of Compounds 3-5 to Give $6-8$. To a $25 \mathrm{~mL}$ round bottomed flask was added the bocprotected diaryldi(2-pyrrolyl)methane $(100 \mathrm{mg})$. The flask was then placed under an argon atmosphere, and anhydrous DCM $(10 \mathrm{~mL})$ was added with stirring. After cooling the reaction mixture to $0{ }^{\circ} \mathrm{C}, 4 \mathrm{M}$ $\mathrm{HCl}(1 \mathrm{~mL})$ in dioxane was added dropwise and allowed to stir overnight at room temperature. The formed precipitate was then collected by suction filtration and washed with DCM to give white solids.

4-(5-((5-((4-Aminobutyl)carbamoyl)-1H-pyrrol-2-yl)di-p-tolylmethyl)-1H-pyrrole-2-carboxamido)butan-1-aminium Chloride (6). The general procedure was followed using $3(100 \mathrm{mg})$ to yield 6 as a white solid in quantitative yield.

${ }^{1} \mathrm{H}$ NMR (400 MHz, DMSO- $\left.d_{6}\right) \delta 11.0(2 \mathrm{H}, \mathrm{s}$, pyrrole- $\mathrm{NH}), 8.1$ $(2 \mathrm{H}, \mathrm{t}, J=8.0 \mathrm{~Hz}$, amide- $\mathrm{NH}), 7.9\left(6 \mathrm{H}, \mathrm{brs}, \mathrm{NH}_{3}\right), 7.1(4 \mathrm{H}, \mathrm{d}, J=8.0$ $\mathrm{Hz}$, phenyl-H), $6.8(4 \mathrm{H}, \mathrm{d}, J=8.0 \mathrm{~Hz}$, phenyl-H), $6.7(2 \mathrm{H}, \mathrm{m}$, pyrrole$\mathrm{H}), 5.7(2 \mathrm{H}, \mathrm{m}$, pyrrole- $\mathrm{H}), 3.2\left(4 \mathrm{H}, \mathrm{q}, J=5.8 \mathrm{~Hz}, \mathrm{CH}_{2}\right), 2.8(4 \mathrm{H}, \mathrm{q}, J$ $\left.=5.8 \mathrm{~Hz}, \mathrm{CH}_{2}\right), 2.3\left(6 \mathrm{H}, \mathrm{s}, \mathrm{CH}_{3}\right), 1.7\left(8 \mathrm{H}, \mathrm{p}, \mathrm{CH}_{2}\right) .{ }^{13} \mathrm{C} \mathrm{NMR}(100$ MHz, DMSO- $\left.d_{6}\right) \delta 160.3,141.9,138.8,135.9,129.2,128.2,127.0$, $110.9,109.8,55.2,38.5,37.8,26.4,24.6,20.6$. MALDI-HRMS calcd (M): 554.3369; observed $(\mathrm{M}+1): 555.4175$.

3, 3'-((5,5'-(Di-p-tolylmethylene) bis (1H-pyrrole-5,2-diyl-2carbonyl))bis(azanediyl))bis(propan-1-aminium) Chloride (7). The general procedure was followed using $4(100 \mathrm{mg})$ to give 7 as a white solid in quantitative yield.

${ }^{1} \mathrm{H}$ NMR (400 MHz, DMSO- $\left.d_{6}\right) \delta 11.0(2 \mathrm{H}, \mathrm{s}$, pyrrole-NH), 8.2 $(2 \mathrm{H}, \mathrm{t}, J=5.2 \mathrm{~Hz}$, amide- $\mathrm{NH}), 7.9\left(6 \mathrm{H}, \mathrm{s}, \mathrm{NH}_{3}\right), 7.1(4 \mathrm{H}, \mathrm{d}, J=8.4$ $\mathrm{Hz}$, phenyl-H), $6.8(4 \mathrm{H}, \mathrm{d}, J=8.4 \mathrm{~Hz}$, phenyl-H), $6.7(2 \mathrm{H}, \mathrm{d}, J=3.6$ $\mathrm{Hz}$, pyrrole- $\mathrm{H}), 5.7(2 \mathrm{H}, \mathrm{d}, J=3.6 \mathrm{~Hz}$, pyrrole- $\mathrm{H}), 3.2(4 \mathrm{H}, \mathrm{q}, J=6.4$ $\left.\mathrm{Hz}, \mathrm{CH}_{2}\right), 2.8\left(4 \mathrm{H}, \mathrm{q}, J=6.4 \mathrm{~Hz}, \mathrm{CH}_{2}\right), 2.3\left(6 \mathrm{H}, \mathrm{s}, \mathrm{CH}_{3}\right), 1.7(4 \mathrm{H}, \mathrm{p}$, $\left.\mathrm{CH}_{2}\right) .{ }^{13} \mathrm{C}$ NMR (100 MHz, DMSO- $\left.d_{6}\right) \delta 160.7,141.9,139.0,135.9$, 129.2 , 128.2, 126.8, 111.0, 110.0, 55.2, 36.8, 35.5, 27.6, 20.6. MALDIHRMS calcd $(M+): 526.3056$; observed $(M+1): 527.3686$; $(M+$ $\mathrm{Na}): 549.3571$.

2,2'-((5,5'-(Di-p-tolylmethylene) bis (1H-pyrrole-5,2-diyl-2carbonyl))bis(azanediyl))bis(ethan-1-aminium) Chloride (8). The general procedure was followed using $\mathbf{5}(100 \mathrm{mg})$ to yield $\mathbf{8}$ as a white solid in quantitative yield.

${ }^{1} \mathrm{H}$ NMR (400 MHz, DMSO- $\left.d_{6}\right) \delta 11.0(2 \mathrm{H}, \mathrm{s}$, pyrrole-NH), 8.3 $(2 \mathrm{H}, \mathrm{t}, J=5.4 \mathrm{~Hz}$, amide- $\mathrm{NH}), 7.9\left(6 \mathrm{H}, \mathrm{br} \mathrm{s}, \mathrm{NH}_{3}\right), 7.1(4 \mathrm{H}, \mathrm{d}, J=8.2$ $\mathrm{Hz}$, phenyl-H), $6.8(4 \mathrm{H}, \mathrm{d}, J=8.2 \mathrm{~Hz}$, phenyl- $\mathrm{H}), 6.7(2 \mathrm{H}, \mathrm{m}$ pyrrole$\mathrm{H}), 5.7(2 \mathrm{H}, \mathrm{m}$, pyrrole- $\mathrm{H}), 3.4\left(4 \mathrm{H}, \mathrm{q}, J=6.0 \mathrm{~Hz}, \mathrm{CH}_{2}\right), 2.9(4 \mathrm{H}, \mathrm{q}, J$ $\left.=6.0 \mathrm{~Hz} \mathrm{CH}_{2}\right), 2.3\left(6 \mathrm{H}, \mathrm{s}, \mathrm{CH}_{3}\right) .{ }^{13} \mathrm{C}$ NMR $\left(100 \mathrm{MHz}, \mathrm{DMSO}-d_{6}\right) \delta$ $160.9,141.7,139.2,135.9,129.1,128.1,126.5,110.94,110.2,55.2$, 38.8, 36.5, 20.5. MALDI-HRMS: calcd (M+): 498.2743; observed (M + 1) 499.3296; $(\mathrm{M}+\mathrm{Na})$ 521.3234.

Molecular Biology. DNA Constructs. cDNAs for rat Kv1.1. 1.2, 1.3 , 1.4, and 1.6 were kindly provided by Professor Olaf Pongs (Institute for Neural Signal Transduction, University of Hamburg, Germany). Concatenation of four $\alpha$ Kv1.1 and/or Kv1.2 subunits as single open reading frames was accomplished ${ }^{50}$ using an intersubunit linker derived from the untranslated regions of the Xenopus $\beta$-globin gene (GenBank accession number J00978) as reported previously. ${ }^{20,21}$

Expression of Kv1 Channels. HEK-293 cells (American Type Culture Collection) were prepared stably expressing Kv1.1, 1.2, 1.3, 
1.4, 1.6 or tandem-linked Kv1.1- and 1.2-homotetramers; additionally, other concatenated DNA constructs encoding Kv1.1-1.2-1.1-1.1, Kv1.1-1.1-1.2-1.2, Kv1.2-1.2-1.1-1.1, Kv1.2-1.1-1.2-1.1, or Kv1.2-1.21.1-1.2 were transiently transfected into HEK-293 cells using Polyfect reagent (Qiagen, Crawley, UK) or Trans-293 transfection reagent (Mirus Bio LLC, Madison, WI, USA).

Whole-Cell Voltage Clamp Recordings and Data Analysis. This was performed as previously outlined, ${ }^{19,21}$ except where specified. In the conventional patch clamp system [EPC10 amplifier (HEKA Elektronik, Lambrecht/Pfalz, Germany)], the recording pipet was filled with an internal solution that contained (in mM): $95 \mathrm{KF}, 30 \mathrm{KCl}$, $1 \mathrm{CaCl}_{2}, 1 \mathrm{MgCl}_{2}, 11$ EGTA, 10 HEPES, $2 \mathrm{~K}_{2} \mathrm{ATP}$ (pH 7.2 with $\mathrm{KOH}$ ), and with fire-polished tips of resistance between 2 and $5 \mathrm{M} \Omega$. The external (bath) medium contained (in $\mathrm{mM}$ ) $135 \mathrm{NaCl}, 5 \mathrm{KCl}, 2$ $\mathrm{CaCl}_{2}, 2 \mathrm{MgCl}_{2}, 5$ Hepes, and 10 sucrose (pH 7.4 with $\mathrm{NaOH}$ ). Whole-cell currents were measured at a holding potential of $-90 \mathrm{mV}$ and then depolarized to $+20 \mathrm{mV}$ for $300 \mathrm{~ms}$ or stepped from the holding potential in $+10 \mathrm{mV}$ increments to $+80 \mathrm{mV}$. Averaged steadystate currents after $200 \mathrm{~ms}$ of activation were calculated. For Kv1.4, currents were determined from the mean peak after activation. Conductance-voltage (gK-V) relations were determined from averaged steady-state currents and normalized relative to the $\mathrm{K}^{+}$ driving force by assuming a reversal potential of $-82 \mathrm{mV}$. Normalized $\mathrm{gK}-\mathrm{V}$ curves were fitted to the Boltzmann function $(\mathrm{I}=[1+\exp \{(V-$ $\left.\left.\left.V_{1 / 2}\right) / k\right\}\right]-1$ ), where $V$ is the membrane (prepulse) potential, $V_{1 / 2}$ is the potential at half-maximal for activation, and $k$ is the slope factor. Time constants for activation $(\tau)$ were determined by fitting the IK amplitudes corresponding to $40-90 \%$ of the maximum at $+20 \mathrm{mV}$ with a single exponential function. Test compounds were dissolved in the extracellular solution as stock solutions of $10 \mathrm{mM}$ and stored at $-20{ }^{\circ} \mathrm{C}$; these were diluted into the extracellular solution in amber tubes to desired concentrations before being applied directly to the recording chamber $(0.5 \mathrm{~mL})$ at a flow rate of $\sim 2 \mathrm{~mL} / \mathrm{min}$.

Automated whole-cell voltage clamping was performed with QPatch 16 (Sophion Bioscience, Ballerup, Denmark) as previously outlined, ${ }^{19,21}$ using the same internal and external solutions as in the conventional system and Qplate pin-holes having resistances of 2-3 $\mathrm{M} \Omega$. Giga-seals were formed upon execution of a combined suction/ voltage protocol with a gradual increase in suction leading to the whole-cell configuration. Compounds were applied via a four-way pipetting robot through integrated glass-coated microfluidic flow channels. Data analysis was performed using an integrated database (Oracle) within QPatch software (Sophion Bioscience). Inhibition by compounds was determined by the Hill equation fit to nine concentrations. The results obtained with QPatch 16 were confirmed by conventional electrophysiological recordings.

Demyelination and ex Vivo Functional Analysis of Conduction in Corpus Callosum of Normal and Cuprizone-Treated Mice. Induction of Demyelination. C57BL/6J male mice, 16 weeks old, were purchased from Harlan UK and housed $\left(21 \pm 2{ }^{\circ} \mathrm{C}\right.$, humidity $36 \pm 2 \%$ at $12 / 12 \mathrm{~h}$ light/dark cycle) in the Bio-Resource Unit of Dublin City University with food and water provided ad libitum. All procedures were approved by the University Research Ethics Committee and licensed by the Health Products Regulatory Authority in accordance with European Communities Council Directive 1986 (86/609/ECC). Experimental animals $(n=7)$ received a modified powdered LabDietH containing $0.2 \%$ cuprizone (Sigma, MO) supplemented chow for 8 weeks, a time sufficient for induction of demyelination, ${ }^{16}$ whereas the control group received a normal diet for the same duration $(n=5)$. Demyelination was assessed by Luxol fast blue staining of brain sections from cuprizone-treated and control mice. Special efforts were made to minimize animal suffering and reduce the number of animals used.

Preparation of Corpus Callosum Slices and Recording of Compound Action Potentials (CAPs). Coronal brain slices (400 $\mu \mathrm{m}$ ) were prepared as previously described. ${ }^{51}$ Briefly, mice were anaesthetized with isofluorane and decapitated. The brain was rapidly removed and placed in ice-cold oxygenated artificial cerebrospinal fluid (aCSF) (composition in mM: $\mathrm{NaCl}, 119$; D-glucose, 11; $\mathrm{NaHCO}_{3}, 26$; $\mathrm{KCl}, 2.5 ; \mathrm{MgSO}_{4}, 1 ; \mathrm{CaCl}_{2}, 2.5 ; \mathrm{NaH}_{2} \mathrm{PO}_{4}, 1 ; \mathrm{pH}$ 7.4) Slices were cut using a vibratome and left to recover in aCSF for $1 \mathrm{~h}$ at room temperature before recording. Electrodes were pulled from borosilicate capillary glass (GC150 F-10, Harvard Apparatus) using a horizontal puller (DMZ universal puller, Germany). Electrodes (2-5 M resistance) were filled with aCSF. The voltage signal was filtered at 5 $\mathrm{kHz}$ and stored for offline analysis using a computer interfaced with a CED/National Instruments A/D board and WinCP software (J. Dempster, Strathclyde University). Slices were perfused with aCSF bubbled with $95 \% \mathrm{O}_{2} / 5 \% \mathrm{CO}_{2}$ maintained at $30{ }^{\circ} \mathrm{C}$. The $\mathrm{CC}$ was stimulated using a monopolar electrode (FHC, Bowdoin, USA) at $0.033 \mathrm{~Hz}$ (100 $\mu$ s duration); the return electrode was a silver/silver chloride wire placed in the recording bath. Extracellular field cAPs were recorded on the contralateral CC for $10 \mathrm{~min}$ after stabilization at 40-50\% maximum response prior to drug application. Signals were amplified by an HS2A headstage (Molecular Devices, USA) connected to an Axoclamp 2B system (Molecular Devices) and a Brownlee 410 Precision preamplifier. A Master 8 (AMPI) timer was used to deliver and time the stimulus trigger. Statistical analysis was performed using either one sample $t$ test or unpaired $t$ test and a two-way ANOVA with Bonferroni's posthoc test. All results were plotted using GraphPad prism software and presented as mean $\pm \mathrm{SEM} ; n$ values refer to the number of animals examined. Control and test experiments were conducted on slices from the same animal. Only slices containing the hippocampus (plates 35-48, Paxinos and Franklin mouse brain atlas with a relative position to the bregma of $2.06 \mathrm{~mm}$ ) were used for recording the cAPs.

Drugs. TTX (Tocris, UK) was aliquoted $(10 \mathrm{mM})$, and $1 \mu \mathrm{M}$ was perfused into the bath. 4-AP was purchased from Sigma-Aldrich, and a $10 \mathrm{mM}$ solution was frozen until use; stocks of $10 \mathrm{mM} \mathrm{6-8}$ were prepared in CSF, stored, and diluted to the working concentrations. After $10 \mathrm{~min}$ of stable baseline recording, 1 and $10 \mu \mathrm{M}$ concentrations of the drug were applied.

Histochemical Analysis. Briefly, mice were transcardially perfused with phosphate buffered saline (PBS) at $\mathrm{pH} 7.4$ supplemented with $4 \%$ formaldehyde. The brains were then rapidly removed, submerged in fixative solution (PBS supplemented with $4 \%$ formaldehyde) overnight at $4{ }^{\circ} \mathrm{C}$ before being placed sequentially in 15 and $30 \%$ sucrose/PBS solutions overnight. The samples were then embedded in optimal cutting temperature compound for cryosectioning (Leica model CM3050 S). Coronal sections $(30 \mu \mathrm{m})$ were prepared the next day and left to dry at room temperature. After staining with Luxol fast blue, the sections were mounted, air-dried, immersed in xylene, coverslipped with DPX mounting medium (Sigma, Ireland), and imaged using a light microscope (Axioscope, Zeiss, Germany) with a DP72 color camera (Olympus).

\section{ASSOCIATED CONTENT}

\section{Supporting Information}

The Supporting Information is available free of charge on the ACS Publications website at DOI: 10.1021/acs.jmedchem.6b01262.

Characterization of target compounds and intermediates and additional biological data (PDF)

Molecular formula strings (CSV)

\section{AUTHOR INFORMATION}

\section{Corresponding Authors}

*Phone: +3531-700-5913; e-mail: kieran.nolan@dcu.ie.

*Phone: +3531-700-7757; e-mail: oliver.dolly@dcu.ie.

\section{Present Address}

(A.A.-S.) Science Department, American University of the Middle East (AUM), Egaila, Kuwait.

\section{Author Contributions}

${ }^{\#}$ These authors contributed equally to this work.

Notes

The authors declare no competing financial interest. 


\section{ACKNOWLEDGMENTS}

The authors thank Prof. Olaf Pongs for generously providing the Kv1 genes and Ms. Sharon Whyte for preparation of this manuscript. The authors wish to acknowledge the DJEI/DES/ SFI/HEA Irish Centre for High-End Computing (ICHEC) for the provision of computational facilities and support. This work was funded by a Principle Investigator grant from Science Foundation Ireland (to J.O.D.), a DCU President scholarship (for S.K.), an Irish Research Council Scholarship (for D.D.), and the Programme for Research in Third Level Institutions (PRTLI) Cycle 4. The PRTLI is cofunded through the European Regional Development Fund (ERDF), part of the European Union Structural Funds Programme 2007-2013.

\section{ABBREVIATIONS USED}

$\alpha \mathrm{DTX}, \alpha$-dendrotoxin; MS, multiple sclerosis; HEK, human embryonic kidney; cAPS, compound action potentials; TTX, tetrodotoxin; PBS, phosphate buffer saline; CC, corpus callosum; 4-AP, 4-aminopyridine; HB, hydrogen bond; DMAP, 4-dimethylaminopyridine; DCM, dichloromethane; TEA, triethylamine; CSF, cerebrospinal fluid; DPM, diaryldi(2-pyrrolyl)methane

\section{REFERENCES}

(1) D’Adamo, M. C.; Catacuzzeno, L.; Di Giovanni, G.; Franciolini, F.; Pessia, $\mathrm{M} . \mathrm{K}(+)$ channelepsy: progress in the neurobiology of potassium channels and epilepsy. Front. Cell. Neurosci. 2013, 7, 1-21.

(2) Smart, S. L.; Lopantsev, V.; Zhang, C. L.; Robbins, C. A.; Wang, H.; Chiu, S. Y.; Schwartzkroin, P. A.; Messing, A.; Tempel, B. L. Deletion of the $\mathrm{K}(\mathrm{V}) 1.1$ potassium channel causes epilepsy in mice. Neuron 1998, 20, 809-819.

(3) Manganas, L. N.; Akhtar, S.; Antonucci, D. E.; Campomanes, C. R.; Dolly, J. O.; Trimmer, J. S. Episodic ataxia type-1 mutations in the Kv1.1 potassium channel display distinct folding and intracellular trafficking properties. J. Biol. Chem. 2001, 276, 49427-49434.

(4) Parcej, D. N.; Scott, V. E.; Dolly, J. O. Oligomeric properties of alpha-dendrotoxin-sensitive potassium ion channels purified from bovine brain. Biochemistry 1992, 31, 11084-11088.

(5) Scott, V. E.; Muniz, Z. M.; Sewing, S.; Lichtinghagen, R.; Parcej, D. N.; Pongs, O.; Dolly, J. O. Antibodies specific for distinct $\mathrm{Kv}$ subunits unveil a heterooligomeric basis for subtypes of alphadendrotoxin-sensitive $\mathrm{K}+$ channels in bovine brain. Biochemistry 1994, 33, 1617-1623.

(6) Scott, V. E.; Rettig, J.; Parcej, D. N.; Keen, J. N.; Findlay, J. B.; Pongs, O.; Dolly, J. O. Primary structure of a beta subunit of alphadendrotoxin-sensitive $\mathrm{K}+$ channels from bovine brain. Proc. Natl. Acad. Sci. U. S. A. 1994, 91, 1637-1641.

(7) Grupe, A.; Schroter, K. H.; Ruppersberg, J. P.; Stocker, M.; Drewes, T.; Beckh, S.; Pongs, O. Cloning and expression of a human voltage-gated potassium channel. A novel member of the RCK potassium channel family. EMBO J. 1990, 9, 1749-1756.

(8) Stuhmer, W.; Ruppersberg, J. P.; Schroter, K. H.; Sakmann, B.; Stocker, M.; Giese, K. P.; Perschke, A.; Baumann, A.; Pongs, O. Molecular basis of functional diversity of voltage-gated potassium channels in mammalian brain. EMBO J. 1989, 8, 3235-3244.

(9) Swanson, R.; Marshall, J.; Smith, J. S.; Williams, J. B.; Boyle, M. B.; Folander, K.; Luneau, C. J.; Antanavage, J.; Oliva, C.; Buhrow, S. A.; Bennet, C.; Stein, R. B.; Kaczmarek, L. K. Cloning and expression of cDNA and genomic clones encoding three delayed rectifier potassium channels in rat brain. Neuron 1990, 4, 929-939.

(10) Kalman, K.; Nguyen, A.; Tseng-Crank, J.; Dukes, I. D.; Chandy, G.; Hustad, C. M.; Copeland, N. G.; Jenkins, N. A.; Mohrenweiser, H.; Brandriff, B.; Cahalan, M.; Gutman, G. A.; Chandy, K. G. Genomic organization, chromosomal localization, tissue distribution, and biophysical characterization of a novel mammalian Shaker-related voltage-gated potassium channel, Kv1.7. J. Biol. Chem. 1998, 273, $5851-5857$.

(11) Coleman, S. K.; Newcombe, J.; Pryke, J.; Dolly, J. O. Subunit composition of Kv1 channels in human CNS. J. Neurochem. 1999, 73, 849-858.

(12) Koch, R. O.; Wanner, S. G.; Koschak, A.; Hanner, M.; Schwarzer, C.; Kaczorowski, G. J.; Slaughter, R. S.; Garcia, M. L.; Knaus, H. G. Complex subunit assembly of neuronal voltage-gated K+ channels. Basis for high-affinity toxin interactions and pharmacology. J. Biol. Chem. 1997, 272, 27577-27581.

(13) Koschak, A.; Bugianesi, R. M.; Mitterdorfer, J.; Kaczorowski, G. J.; Garcia, M. L.; Knaus, H. G. Subunit composition of brain voltagegated potassium channels determined by hongotoxin-1, a novel peptide derived from Centruroides limbatus venom. J. Biol. Chem. 1998, 273, 2639-2644.

(14) Shamotienko, O. G.; Parcej, D. N.; Dolly, J. O. Subunit combinations defined for $\mathrm{K}+$ channel $\mathrm{Kv} 1$ subtypes in synaptic membranes from bovine brain. Biochemistry 1997, 36, 8195-8201.

(15) Judge, S. I.; Bever, C. T., Jr. Potassium channel blockers in multiple sclerosis: neuronal $\mathrm{Kv}$ channels and effects of symptomatic treatment. Pharmacol. Ther. 2006, 111, 224-259.

(16) Bagchi, B.; Al-Sabi, A.; Kaza, S.; Scholz, D.; O’Leary, V. B.; Dolly, J. O.; Ovsepian, S. V. Disruption of myelin leads to ectopic expression of $\mathrm{K}(\mathrm{V}) 1.1$ channels with abnormal conductivity of optic nerve axons in a cuprizone-induced model of demyelination. PLoS One 2014, 9, e87736.

(17) Grissmer, S.; Nguyen, A. N.; Aiyar, J.; Hanson, D. C.; Mather, R. J.; Gutman, G. A.; Karmilowicz, M. J.; Auperin, D. D.; Chandy, K. G. Pharmacological characterization of five cloned voltage-gated $\mathrm{K}+$ channels, types Kv1.1, 1.2, 1.3, 1.5, and 3.1, stably expressed in mammalian cell lines. Mol. Pharmacol. 1994, 45, 1227-1234.

(18) Al-Sabi, A.; Kaza, S.; Le Berre, M.; O’Hara, L.; Bodeker, M.; Wang, J.; Dolly, J. O. Position-dependent attenuation by Kv1.6 of Ntype inactivation of Kv1.4-containing channels. Biochem. J. 2011, 438, 389-396.

(19) Daly, D.; Al-Sabi, A.; Kinsella, G. K.; Nolan, K.; Dolly, J. O. Porphyrin derivatives as potent and selective blockers of neuronal Kv1 channels. Chem. Commun. (Cambridge, U. K.) 2015, 51, 1066-1069.

(20) Al-Sabi, A.; Shamotienko, O.; Dhochartaigh, S. N.; Muniyappa, N.; Le Berre, M.; Shaban, H.; Wang, J.; Sack, J. T.; Dolly, J. O. Arrangement of Kv1 alpha subunits dictates sensitivity to tetraethylammonium. J. Gen. Physiol. 2010, 136, 273-282.

(21) Al-Sabi, A.; Kaza, S. K.; Dolly, J. O.; Wang, J. Pharmacological characteristics of Kv1.1- and Kv1.2-containing channels are influenced by the stoichiometry and positioning of their alpha subunits. Biochem. J. 2013, 454, 101-108.

(22) Long, S. B.; Campbell, E. B.; Mackinnon, R. Crystal structure of a mammalian voltage-dependent Shaker family $\mathrm{K}+$ channel. Science 2005, 309, 897-903.

(23) Ader, C.; Schneider, R.; Hornig, S.; Velisetty, P.; Wilson, E. M.; Lange, A.; Giller, K.; Ohmert, I.; Martin-Eauclaire, M. F.; Trauner, D.; Becker, S.; Pongs, O.; Baldus, M. A structural link between inactivation and block of a K+ channel. Nat. Struct. Mol. Biol. 2008, 15, 605-612.

(24) Gradl, S. N.; Felix, J. P.; Isacoff, E. Y.; Garcia, M. L.; Trauner, D. Protein surface recognition by rational design: nanomolar ligands for potassium channels. J. Am. Chem. Soc. 2003, 125, 12668-12669.

(25) James, D. A.; Arnold, D. P.; Parsons, P. G. Potency and selective toxicity of tetra(hydroxyphenyl)- and tetrakis(dihydroxyphenyl)porphyrins in human melanoma cells, with and without exposure to red light. Photochem. Photobiol. 1994, 59, 441-447.

(26) Bowie, J. U.; Luthy, R.; Eisenberg, D. A method to identify protein sequences that fold into a known three-dimensional structure. Science 1991, 253, 164-170.

(27) Colovos, C.; Yeates, T. O. Verification of protein structures: patterns of nonbonded atomic interactions. Protein Sci. 1993, 2, 15111519.

(28) Laskowski, R. A.; Rullmann, J. A.; MacArthur, M. W.; Kaptein, R.; Thornton, J. M. AQUA and PROCHECK-NMR: programs for 
checking the quality of protein structures solved by NMR. J. Biomol. NMR 1996, 8, 477-486.

(29) Morris, G. M.; Huey, R.; Lindstrom, W.; Sanner, M. F.; Belew, R. K.; Goodsell, D. S.; Olson, A. J. AutoDock4 and AutoDockTools4: Automated docking with selective receptor flexibility. J. Comput. Chem. 2009, 30, 2785-2791.

(30) Ziskin, J. L.; Nishiyama, A.; Rubio, M.; Fukaya, M.; Bergles, D. E. Vesicular release of glutamate from unmyelinated axons in white matter. Nat. Neurosci. 2007, 10, 321-330.

(31) Crawford, D. K.; Mangiardi, M.; Xia, X.; Lopez-Valdes, H. E.; Tiwari-Woodruff, S. K. Functional recovery of callosal axons following demyelination: a critical window. Neuroscience 2009, 164, 1407-1421.

(32) Sinha, K.; Karimi-Abdolrezaee, S.; Velumian, A. A.; Fehlings, M. G. Functional changes in genetically dysmyelinated spinal cord axons of shiverer mice: role of juxtaparanodal $\mathrm{Kv} 1 \mathrm{family} \mathrm{K}+$ channels. $J$. Neurophysiol. 2006, 95, 1683-1695.

(33) McCormack, K.; Tanouye, M. A.; Iverson, L. E.; Lin, J. W.; Ramaswami, M.; McCormack, T.; Campanelli, J. T.; Mathew, M. K.; Rudy, B. A role for hydrophobic residues in the voltage-dependent gating of Shaker K+ channels. Proc. Natl. Acad. Sci. U. S. A. 1991, 88, 2931-2935.

(34) Blom, S. M.; Rottlander, M.; Kehler, J.; Bundgaard, C.; Schmitt, N.; Jensen, H. S. From pan-reactive KV7 channel opener to subtype selective opener/inhibitor by addition of a methyl group. PLoS One 2014, 9, e100209.

(35) Lange, W.; Geissendorfer, J.; Schenzer, A.; Grotzinger, J.; Seebohm, G.; Friedrich, T.; Schwake, M. Refinement of the binding site and mode of action of the anticonvulsant Retigabine on KCNQ K + channels. Mol. Pharmacol. 2009, 75, 272-280.

(36) Gean-Marton, A. D.; Vezina, L. G.; Marton, K. I.; Stimac, G. K.; Peyster, R. G.; Taveras, J. M.; Davis, K. R. Abnormal corpus callosum: a sensitive and specific indicator of multiple sclerosis. Radiology 1991, $180,215-221$.

(37) Craner, M. J.; Newcombe, J.; Black, J. A.; Hartle, C.; Cuzner, M. L.; Waxman, S. G. Molecular changes in neurons in multiple sclerosis: altered axonal expression of Nav1.2 and Nav1.6 sodium channels and $\mathrm{Na}+/ \mathrm{Ca} 2+$ exchanger. Proc. Natl. Acad. Sci. U. S. A. 2004, 101, 81688173.

(38) Bostock, H.; Sears, T. A. The internodal axon membrane: electrical excitability and continuous conduction in segmental demyelination. J. Physiol. 1978, 280, 273-301.

(39) Wang, H.; Kunkel, D. D.; Schwartzkroin, P. A.; Tempel, B. L. Localization of Kv1.1 and Kv1.2, two K channel proteins, to synaptic terminals, somata, and dendrites in the mouse brain. J. Neurosci. 1994, 14, 4588-4599.

(40) Dodson, P. D.; Barker, M. C.; Forsythe, I. D. Two heteromeric $\mathrm{Kvl}$ potassium channels differentially regulate action potential firing. $J$. Neurosci. 2002, 22, 6953-6961.

(41) Jensen, H. B.; Ravnborg, M.; Dalgas, U.; Stenager, E. 4Aminopyridine for symptomatic treatment of multiple sclerosis: a systematic review. Ther. Adv. Neurol. Disord. 2014, 7, 97-113.

(42) Lee, J. H.; Lee, B. H.; Choi, S. H.; Yoon, I. S.; Pyo, M. K.; Shin, T. J.; Choi, W. S.; Lim, Y.; Rhim, H.; Won, K. H.; Lim, Y. W.; Choe, H.; Kim, D. H.; Kim, Y. I.; Nah, S. Y. Ginsenoside Rg3 inhibits human Kv1.4 channel currents by interacting with the Lys531 residue. Mol. Pharmacol. 2007, 73, 619-626.

(43) Martos, V.; Bell, S. C.; Santos, E.; Isacoff, E. Y.; Trauner, D.; de Mendoza, J. Molecular recognition and self-assembly special feature: Calix[4]arene-based conical-shaped ligands for voltage-dependent potassium channels. Proc. Natl. Acad. Sci. U. S. A. 2009, 106, 10482-10486.

(44) Marzian, S.; Stansfeld, P. J.; Rapedius, M.; Rinne, S.; NematianArdestani, E.; Abbruzzese, J. L.; Steinmeyer, K.; Sansom, M. S.; Sanguinetti, M. C.; Baukrowitz, T.; Decher, N. Side pockets provide the basis for a new mechanism of $\mathrm{Kv}$ channel-specific inhibition. Nat. Chem. Biol. 2013, 9, 507-513.

(45) Pegoraro, S.; Lang, M.; Dreker, T.; Kraus, J.; Hamm, S.; Meere, C.; Feurle, J.; Tasler, S.; Prutting, S.; Kuras, Z.; Visan, V.; Grissmer, S.
Inhibitors of potassium channels $\mathrm{KV} 1.3$ and IK-1 as immunosuppressants. Bioorg. Med. Chem. Lett. 2009, 19, 2299-2304.

(46) Rangaraju, S.; Khoo, K. K.; Feng, Z. P.; Crossley, G.; Nugent, D.; Khaytin, I.; Chi, V.; Pham, C.; Calabresi, P.; Pennington, M. W.; Norton, R. S.; Chandy, K. G. Potassium channel modulation by a toxin domain in matrix metalloprotease 23. J. Biol. Chem. 2010, 285, 91249136.

(47) Yang, Q.; Du, L.; Wang, X.; Li, M.; You, Q. Modeling the binding modes of Kv1.5 potassium channel and blockers. J. Mol. Graphics Modell. 2008, 27, 178-187.

(48) Huey, R.; Morris, G. M.; Olson, A. J.; Goodsell, D. S. A semiempirical free energy force field with charge-based desolvation. J. Comput. Chem. 2007, 28, 1145-1152.

(49) Morris, G. M.; Goodsell, D. S.; Huey, R.; Olson, A. J. Distributed automated docking of flexible ligands to proteins: parallel applications of AutoDock 2.4. J. Comput.-Aided Mol. Des. 1996, 10, 293-304.

(50) Sokolov, M. V.; Shamotienko, O.; Dhochartaigh, S. N.; Sack, J. T.; Dolly, J. O. Concatemers of brain Kv1 channel alpha subunits that give similar $\mathrm{K}+$ currents yield pharmacologically distinguishable heteromers. Neuropharmacology 2007, 53, 272-282.

(51) Swanson, T. H.; Krahl, S. E.; Liu, Y. Z.; Drazba, J. A.; Rivkees, S. A. Evidence for physiologically active axonal adenosine receptors in the rat corpus callosum. Brain Res. 1998, 784, 188-198. 